\title{
When is a MAX not the MAX? How news resolves information uncertainty
}

\section{Article}

\section{Accepted Version}

Creative Commons: Attribution-Noncommercial-No Derivative Works 4.0

Tao, R., Brooks, C. and Bell, A. R. (2020) When is a MAX not the MAX? How news resolves information uncertainty. Journal of Empirical Finance, 57. pp. 33-51. ISSN 0927-5398 doi: https://doi.org/10.1016/j.jempfin.2020.03.002 Available at https://centaur.reading.ac.uk/89795/

It is advisable to refer to the publisher's version if you intend to cite from the work. See Guidance on citing.

To link to this article DOI: http://dx.doi.org/10.1016/j.jempfin.2020.03.002

Publisher: Elsevier

All outputs in CentAUR are protected by Intellectual Property Rights law, including copyright law. Copyright and IPR is retained by the creators or other copyright holders. Terms and conditions for use of this material are defined in the End User Agreement.

\section{www.reading.ac.uk/centaur}

\section{CentAUR}

Central Archive at the University of Reading

Reading's research outputs online 


\title{
Tomorrow's Fish and Chip Paper? Slowly incorporated News and the Cross-section of Stock Returns
}

\author{
Ran Tao * $\quad$ Chris Brooks ${ }^{\dagger} \quad$ Adrian Bell ${ }^{\ddagger}$
}

March 8, 2020

\begin{abstract}
A large literature debates the link between news and investor decision making. Relying on unique U.S. firm-level news data between 1979 and 2016, we document a crosssectional difference in the speed of diffusion of the information contained in news. We distinguish news articles as being either slowly or quickly incorporated into contemporaneous stock prices. The return spread between these two types of news yields a statistically significant profitability (139 basis points per month) and this effect cannot be explained by other well-known risk factors. By employing novel attention data (Google Search Volume Index and Bloomberg News Readerships Index), we find that this news-induced anomaly can be attributed to limited-attention theory where firmspecific news is not read by investors. Our research refines the role of news regarding information dissemination in the financial markets.
\end{abstract}

JEL classifications: G12; G14

Keywords: News sentiment; information dissemination; stock return predictability; investor attention; anomalies

We are grateful to Chris Adcock (the Editor), an Associate Editor, and two anonymous referees for constructive comments and suggestions. We thank Tian Han for advice about textual data mining and the Google Cloud Platform (GCP) providing research credits for our sentiment analysis. We also thank C.S Agnes Cheng, Steven Young, Simone Varotto, Tony Moore, the 2019 BAFA doctoral conference and the FMA Europe Doctoral Student Consortium for useful comments. All errors are our own.

${ }^{*}$ ICMA Centre, Henley Business School, University of Reading. E-mail: ran.tao@pgr.reading.ac.uk

${ }^{\dagger}$ ICMA Centre, Henley Business School, University of Reading. E-mail: c.brooks@icmacentre.ac.uk

${ }^{\ddagger}$ ICMA Centre, Henley Business School, University of Reading. E-mail: a.r.bell@icmacentre.ac.uk 


\section{Introduction}

News articles usually have limited-time effects due to quick information transmission. This intuition can be summed up by the well-known idiom that 'today's news is tomorrow's fish and chip paper" 1 Although today's financial markets build on a continuous flow of news, the analogy does not apply if we follow the existing body of news predictability studies. So far, the evidence has revealed that returns following news arrivals are somewhat predictable. While the literature attributes such a predictable pattern to either investor underreaction or overreaction based on ex-post measures ${ }^{2}$ a close look at the ex ante interaction between the information embedded in news articles and contemporaneous stock reactions seems to be ignored and might be worthwhile.

Arguably, the information conveyed by news articles will start to be incorporated into prices immediately on its arrival, and so it is possible that different news articles might incorporate information into stock markets at different speeds. For example, one negative news event could impact on the stock return gradually and persistently whereas the influence of another might be quick and prominent. Therefore, in this paper we take a unique perspective by studying ex ante instances when news tone does not match with contemporaneous stock reactions. The essential question we ask is: what is the impact of future return performance when contemporaneous stock reactions mismatch with the tone of news flows?

There are two important building blocks to derive our central hypothesis: First, the monthly aggregated news sentiment scores can serve as a proxy for a firm's economic fundamentals. Second, investors tend to underreact to the news momentum phenomenon (see Wang, Zhang, and Zhu (2018)). To measure how quickly information is incorporated in an ex ante instance, we use a sequential double-sorted approach based on monthly stock returns and news sentiment scores. The idea is that there should be a monotonic relationship between stock returns and aggregate news sentiment scores at a monthly horizon (e.g., Wang et al. (2018)). If there is a mismatch between the two, it is likely that investors have underreacted to news fundamentals and a delayed reaction will be observed.

By allowing for a heterogeneous relationship between contemporaneous stock returns and news tone, we are able to classify a news item in terms of whether it conveys information

\footnotetext{
${ }^{1}$ In the UK, fish and chips (a takeaway treat) was traditionally wrapped in newspaper in order to absorb grease. This demonstrated that a newspaper was only valuable for the news it carried on the day of publication.

${ }^{2}$ For example, Chan (2003) conclude that investors underreact to public information and overreact to private information by measuring long-run stock return performance; Tetlock (2007) documents an investor overreaction pattern by constructing a VAR (Vector Autoregression) model. Other related studies include Tetlock, Saar-Tsechansky, and Macskassy (2008), Garcia (2013), Ahmad, Han, Hutson, Kearney, and Liu (2016), Jiang, Li, and Wang (2017), and Kräussl and Mirgorodskaya (2017).
} 
quickly or slowly to the markets. For instance, a stock which has positive stock-related news stories accompanied by modest or perhaps negative returns might suggest an inability to incorporate information effectively. In other words, this fundamental information is not yet incorporated into stock prices. As such, a central hypothesis underlying this research design is that the predictable future returns will be stronger among these slowly incorporated (SI) news stocks than those where news is quickly incorporated (QI).

We perform the following analysis: we first assign a sentiment score to each news article by employing the Loughran and McDonald (2011) dictionary method. This dictionary is based on the 'bag-of-words' model which pre-labels each word as either positive, negative, model-weak, litigious, etc. This technique is advantageous as it can gauge business tone. We then define an SI news stock and a QI news stock in two ways. Under the assumption that stock returns are a function of stock-related news, we evaluate the investor reaction to news based on the current monthly stock return. Specifically, we construct monthly double-sorted portfolios by sorting stocks into terciles based on their current returns and further sorting each return group into another tercile based on their aggregate news sentiment scores. The good (bad) news accompanying negative (positive) stock returns is defined as slowly incorporated news, whereas news with matching stock returns we refer to as quickly incorporated news.

Next, we examine the post-formation stock returns of these two types of news-influenced stocks. To do so, we compute equally-weighted average portfolio returns for the two groups in the following month. A long/short portfolio consisting of buying the slowly incorporated good news (LRHS) stocks and selling the slowly incorporated bad news (HRLS) stocks generates abnormal future returns even after controlling for well-known risk factors. In sharp contrast, the other strategy of buying quickly incorporated good news (HRHS) stocks and selling quickly incorporated bad news (LRLS) stocks earns negative future returns. The profitability figures for both sets of portfolios are robust to various specifications. By including quintile portfolios, splitting into different sample periods, using a weekly frequency of analysis and employing a different measure of news sentiment scores, the results are quantitatively similar, suggesting that these SI news effects are unlikely to arise from data mining or biased measures.

To further understand what drives SI news effects, we propose two hypotheses. One explanation follows limited attention theory, suggesting that investors tend to narrow down their focus to a few stocks instead of dispersing their selection evenly throughout the entire stock universe, see (Hirshleifer, Lim, and Teoh, 2009). To be more specific, these limitedattention investors, especially retail investors, tend to concentrate on certain stocks such as big size, high media coverage, high trading volume stocks and firms with a high level of 
analyst coverage. Undoubtedly, these firms have a better information environment where investors face less information asymmetry and therefore it is more efficient for them to react to news. In contrast, small and less-information rich firms are less likely to be under the spotlight, causing delayed reactions to news by investors.

Second, the speed of incorporation could result from the different nature of the news item, namely complexity and informativeness. Prior literature has studied the relationship between textual complexity and corresponding market reactions (Loughran and McDonald, 2014; Lawrence, 2013). For example, Loughran and McDonald (2014) document that the readability of financial disclosures has a significant impact on post-filing date returns, analyst dispersion, and standardized unexpected earnings (SUE). Umar (2008) finds that a long news headlines lead to a 40-basis point return under-reaction on the Seeking Alpha forum. Thus, it is likely that slowly incorporated news conveys information that is challenging to interpret for less sophisticated investors. Moreover, the literature also argues that different news articles exhibit different informativeness features. You, Zhang, and Zhang (2017) show that marketoriented media tend to be more comprehensive in reporting corporate events compared to state-controlled media. Presumably, investors might react quickly to these more informative news articles but under-react to those less informative articles which are labelled as slowly incorporated news in our setting.

To test the two hypotheses, we examine whether slowly incorporated news is concentrated among firms with less attention, proxied by small size, low media coverage, and low trading volume. We find consistent evidence that slowly incorporated news has stronger effects among low-attention firms. Furthermore, we investigate limited attention theory by applying two direct attention proxies: the Google Search Volume Index (SVI) and Bloomberg News Reading Activity Index (AIA, Abnormal Institutional Attention). As conventional attention proxies cannot guarantee that investors are actually reading firm-specific news (albeit they have high coverage), the literature utilises these alternative measures in order to better capture investor attention (Engelberg and Gao, 2011). Our results suggest that SI news with low investor attention, particularly without retail investor attention, predicts stronger stock returns. In contrast, we find mixed evidence for cross-sectional differences between the effects of news as measured by textual complexity and by informativeness features. While SI news is not exclusively earnings-irrelevant and too hard to read (i.e. low readability), we do find that these news articles tend to be less accurate (proxied by business uncertainty tone) and less comprehensive (measured by article length). Collectively, these results do not systemically support the notion that SI news is more complex and less informative.

Our paper contributes to the literature in several aspects: First, we propose a novel ex ante approach to categorise news articles as slowly incorporated and quickly incorpo- 
rated into prices. The predictable return patterns after the news will only emerge when ex ante news sentiment scores and contemporaneous returns are mismatched. Second, our results support limited-attention theory in which the investor attention radar keeps certain stocks below the horizon and therefore they react to stock-related news slowly (e.g., Da, Gurun, and Warachka (2014) and Fang and Peress (2009)). Finally, our findings also have some implications for practitioners. The refined predictive model based on both news and contemporaneous returns provides a promising avenue for a potentially profitable trading strategy.

The rest of the paper is organised as follows: Related literature and hypothesis development will be discussed in Section 2. Section 3 presents the news data collection process and how we define SI and QI news. Section 4 reports baseline empirical results, additional robustness tests and empirical designs for two potential explanations of our findings. In the final section, we present our conclusions and outline further directions for research.

\section{Related Literature and Hypothesis Development}

Our paper is related to several existing strands of the literature. First, our research is relevant to the topic of investor attention. The literature argues that it is either limitedattention theory or prominence theory that determines the impact of news on stock prices. Limited-attention theory, as suggested by Fang and Peress (2009), explains that a firm with no media coverage earns higher returns than others, indicating that no attention can lead to stock price rises. In contrast, prominence theory believes in the value of the visibility. In other words, more media coverage leads to better asset returns - e.g., Hillert, Jacobs, and Müller (2014) finds that the media makes momentum profitability. They attribute this to an overconfidence-driven overreaction where investors tend to be attracted by a news story with high coverage and therefore are overly optimistic. Recently, a new source of data has added to the investor attention literature, namely Google SVI, Bloomberg AIA (Engelberg and Gao, 2011; Ben-Rephael, Da, and Israelsen, 2017). Following the majority of the previous literature, we examine various measures of attention including firm-specific media coverage, firm-level Google SVI and Bloomberg AIA. The results support limited-attention theory where a firm within an inferior information environment and with less attention tends to have news that is slowly reacted to and thus achieves better stock returns.

Second, the readability literature is also relevant to our study. Acccounting research documents that the complexity of corporate releases has certain impacts on post-filing stock returns (Lawrence, 2013; Dougal, Engelberg, Garcia, and Parsons, 2012; Chakrabarty, Seetharaman, Swanson, and Wang, 2018). A major measure of document complexity is the 
'Fog Index' - which is defined as a linear combination of average sentence length and the percentage of complex words. Loughran and McDonald (2014) argues that the complexity of $10-K_{s}$ certainly affects investor reaction as simple and concise materials take investors and analysts much less time to digest and to determine the valuation-relevant information. Moreover, news materials can exhibit similar effects (Umar, 2008). Inspired by this strand of the literature, we investigate whether our identified slow information incorporation is largely attributed to document complexity. However, we do not find any strong evidence to support this argument.

In addition, several studies of media characteristics are related to this paper. Fedyk and Hodson (2017) find that 'Front page' news in Bloomberg terminals always induces higher trading volumes and larger price drifts. In contrast, the reaction to 'non-front page' news stories is much smaller. Boulland, Degeorge, and Ginglinger (2017) document that the market quick reaction to firm-specific events is after which these news items are printed in English and circulated in electronic format. Engelberg and Parsons (2011) argue that media outlets seem to have different broadcasting radii, where local mass media significantly drives local trading behaviour. Newspaper articles published by state-owned newspapers and market-oriented newspapers exhibit different effects upon stock performance (You et al. 2017).

Our research is also inspired by the link between textual analysis and investor decision making (Tetlock, 2007; Tetlock et al., 2008; Garcia, 2013; Hadzic, Weinbaum, and Yehuda, 2015; Ahmad et al., 2016, Jiang et al., 2017; Caporale, Spagnolo, and Spagnolo, 2018). Tetlock (2007) documents that the tone of the Abreast Of The Market column can predict DJIA index price movements on the next trading day, and is followed by a subsequent reversal. Garcia 2013) further confirms this effect by using different newspaper columns and finds that the market response to news tone is stronger during periods of recession. In addition, firm-level studies are explored in terms of media tone - e.g., Tetlock et al. (2008) document that firm-level media tone can predict earnings surprises and daily stock returns. Hadzic et al. (2015) shows that investors sometimes misunderstand public information and will reverse the stock return in the following months. Ahmad et al. (2016) select 20 big firms with consecutive daily news and categorises this news into being either informative or noise. They show that informative news can predict persistent future returns whereas 'noise news' forecasts a subsequent reversal. Moving to the intra-day frequency, the effects of media tone becomes fairly simple (i.e., good news predicts positive asset returns while bad news predicts negative returns) (Jiang et al., 2017). Our study adds to this literature as slowly incorporated news can be shown to forecast asset returns.

Finally, this paper also touches upon momentum and reversal literature. Return contin- 
uations and reversals are normally measured on a weekly or monthly basis. In particular, momentum strategies are operationalised by constructing a portfolio with a formation period from 3- to 12-months whereas the short-term reversal is measured on a monthly basis (Jegadeesh and Titman, 1993, 1995, 2001). Wang et al. (2018) study news momentum on a monthly basis and find that the media tone of firm-level news flows is more likely consistent. Our research adds to this literature by highlighting media-induced anomalies. That is, slowly incorporated news tends to lead to momentum profits, whereas quickly incorporated news generates return reversals.

Based on these studies, we develop our central hypothesis. It has been widely accepted that both investor underreaction and overreaction can cause predictable return patterns following measurable news. Chan (2003) documents that investors underreact to public information (i.e., measurable DJNS news) and overreact to private information while Tetlock et al. (2008) find that stock prices will have positive drifts after good DJNS news and become negative when the news is bad. Wang et al. (2018) document a news momentum phenomenon: stocks in the highest news sentiment score portfolio will typically continue to have high news sentiment scores in the next month, and vice versa. Their further results show that the future return will be high (low) for those stocks from the highest (lowest) news sentiment score portfolio. On the other hand, Tetlock (2007) documents an investor overreaction pattern: the tone of the Abreast Of The Market column positively predicts stock index price movements on the next trading day and negatively predicts it in the short term future, suggesting a return reversal. Borrowing these findings and applying them to our research setting, it seems reasonable to infer that investors will underreact to these measurable news stories when contemporaneous stock reactions do not quickly match with the news tone. As a result, one can expect a delayed reaction in the following months. On the other hand, investors might overreact to these news items when both news sentiment scores and stock returns are in the top (bottom) bins.

Collectively, this discussion motivates our central hypothesis. The future return pattern regarding SI and QI news is as follows:

Hypothesis: SI news tends to lead to high future returns and QI news tends to produce low future returns. 


\section{Data and Methodology}

\subsection{News Collection and Sentiment Analysis}

Our primary data comprises news taken from Dow Jones Newswire Archive $3^{3}$ It contains all of the news from the Dow Jones newswire and all Wall Street Journal newspapers. To examine slowly incorporated and quickly incorporated news and their cross-sectional return patterns, we construct a sample of firm-level news released by the common U.S. stocks listed on the NYSE, AMEX and NASDAQ between 1979 and 2016.

The firm-level news articles are collected with a few filtering conditions. To be included in our sample, firms should have at least one news story disseminated by the Dow Jones Newswire. Second, we require stocks to have prices greater than one dollar and non-missing values of market capitalisation and book-to-market ratio. Third, we only select firms listed on the NYSE, AMEX and NASDAQ stock exchanges with share codes 10 or 11 as these two share types allow us to retrieve all U.S. common stocks.

To obtain all potential news items from the Dow Jones Newswire Archive, we downloaded the historical name change file from the Center for Research in Security Prices (CRSP). All firm identifiers are changed to their historical names/tickers according to the period in which they were officially registered. Eventually, via this method, we identified 21,242 stocks from the database.

We assign news items to the particular firm permco (CRSP's permanent company identifier) if the ticker tagged in the news matches the stock's within the valid period. For example, the ticker symbol for Apple Inc is AAPL, which would also be tagged in the news if the story is relevant to the Apple company. But arguably, this method has pitfalls where news will be collected regardless of how relevant it is for the firm. Presumably, an article analysing the cell phone industry certainly differs from a news article addressing iPhone products specifically in terms of the likely strength of any stock price reaction. Thus, in the Appendix, we perform robustness checks by collecting firm-level news with more strict conditions to increase its relevance.

Through this method, our initial sample has 14,079 Dow Jones news firms out of 21,242 targets from the CRSP universe between July 1979 and December 2016, 13,406 of which have at least ten news items in the whole lifespan. One concern is that since the Dow Jones Newswire database is underdeveloped and somehow incomplete during the early stage, it might be the case that a number of firms have news reports in the Newswire but these

\footnotetext{
${ }^{3}$ Dow Jones Newswire is a global leading real-time news product and is commonly used in many research papers - e.g., (Tetlock, 2010, 2011; Engelberg, Reed, and Ringgenberg, 2012, Engelberg, McLean, and Pontiff, 2018).
} 
articles do not have tickers attached. Therefore, our procedure does not capture these firmspecific news items. On the other hand, these missing firms might not be covered by the Newswire at all. In an unreported test, we compare two statistics: the total number of stocks from the CRSP universe and the number of matched Dow Jones News stocks. During the early period (1979 to 1995), the percentage of stocks covered by measurable Dow Jones news reports is around $20 \%$ to $30 \%$. However, this statistic increases rapidly to over $95 \%$ after 1995. As a result, there is strong evidence to believe that most missing firms are clustered in the early years. To further allay readers' potential concerns that our baseline results might be significantly influenced by these unmatched firms in the early years, we later perform a sub-sample analysis and the results remain positive in all four sub-periods. Overall, concerning the total number of firm-level news items, our sample stocks have 10,751,978 news observations in total. On average, there are 763 news articles for each firm.

In addition, we also plot the histogram of news observations. The distribution of our news data is highly skewed. As can be seen in the Figure 1, the percentage of firms with larger news items gradually decreases. To be more specific, there are 4492 firms with 1 to 100 news items, accounting for $32 \%$ of total sample. This statistic declines to $15 \%$ when it comes to firms with 100-200 news items, and only $8 \%$ for those with 200-300 news items. Collectively, it can be concluded that most news items belong to a small number of firms. This pattern is consistent with Tetlock et al. (2008), who find that large firms tend to have news coverage every day whereas small firms only have sparse observations. One implication regarding this property is that our baseline results might be driven by the small size effect. However, our further robustness checks have eliminated this concern as we remove stocks whose prices are below $\$ 5$ per share and our results remain positive. We also incorporate the size factor into the Fama-French factor models which should also soak up this effect.

Insert Figure 1 here

To quantify the sentiment from our firm-specific news, we employed the Loughran and McDonald dictionary method as this approach builds on the work of Henry (2008). 4 This sentiment analysis method is a reliable and popular technique as it is tailored specifically to finance applications (e.g., see Loughran and McDonald (2011) and Loughran and McDonald (2015)). For instance, the word "abandoned" is pre-assigned as a negative sentiment word

\footnotetext{
${ }^{4}$ Although Henry (2008) is the first work that contributes to sentiment analysis, we do not employ the word list developed by therein for two reasons: First, Henry's list only has a very limited number of sentiment words (e.g., 85 negative words) whereas that of Loughran and McDonald (2011) includes 2329 such words. More importantly, the most frequent LM negative words based on 10-K annual reports such as loss, losses, claims, impairment, against, adverse, restated, adversely, restructuring, and litigation, do not appear in Henry's list. This suggests that Henry's dictionary may not sufficiently capture all potential negative tone from the text.
} 
in this dictionary. Any document which contains the word "abandoned" will be counted and increases the negative percentage. Although our core analysis builds on the sentiment score measured by this method, we later consider employing other sentiment analysis to justify that our results are not sensitive to different tools.

The very first step is to construct an article-level sentiment score. For each news story, we adapt the method proposed by Garcia (2013), constructing an article-level news sentiment score using both positive and negative sentiment words as indicators. Specifically, the articlelevel news sentiment score is computed by taking the number of positive words minus negative words divided by the total number of words.

In the second step, we standardise these news sentiment scores at a stock-level. For each stock, the news sentiment score is standardised by subtracting the rolling mean of the previous 12 months and dividing by the standard deviation of the same period for each firm. In the following paragraphs, $N S S$ is used to denote the standardised news sentiment score.

The final step is aggregation. To fit the $N S S$ into our empirical setting (i.e., monthly portfolio analysis), we aggregate these $N S S$ every month. $N S S_{i, t}$ represents the aggregated news sentiment score standardised in a time-series manner for each firm $i$ in each month $t$.

$$
\begin{gathered}
n s s=\frac{\text { No. of pos }- \text { No. of neg }}{\text { total number of words }} \\
N S S=\frac{n s s-\mu_{n s s}}{\sigma_{n s s}}
\end{gathered}
$$

where $\mu_{n s s}$ is the rolling mean of the previous 12 months news sentiment score (denoted by $N S S)$ and $\sigma_{n s s}$ is the rolling standard deviation of $N S S$ during the same period for each firm. In other words, $N S S$ is standardised in a time-series manner, separately for each firm.

\subsection{Slowly and quickly incorporated News}

In this subsection, we derive two building blocks of this paper: (1) the monthly aggregated news sentiment scores reflect a firm's economic fundamentals. (2) investors underreact to news momentum. Specifically, Wang et al. (2018) document a news momentum phenomenon: By aggregating news articles' sentiment scores on a monthly basis for each firm, they find that stocks in the highest (lowest) news sentiment score portfolio continue to have high (low) news sentiment scores in the future. Such a pattern is driven by the firm's fundamentals. When linking this news momentum pattern with stock prices, they find that those stocks with the highest (lowest) news sentiment scores have high (low) future returns, which is caused by investors' underreaction. 
Our empirical design of SI and QI news portfolio construction builds on these two blocks. To measure how quickly information is incorporated, we use a sequential double-sorted approach based on monthly stock returns and news sentiment scores. The idea is that there should be a monotonic relationship between stock returns and aggregated news sentiment scores at a monthly horizon (e.g., Wang et al. (2018)). If there is a mismatch between the two patterns, it is likely that investors have underreacted to news fundamentals and a delayed reaction will be observed.

To ensure that the stock return we utilise is firm-specific, we calculate the DGTWadjusted returns following Daniel, Grinblatt, Titman, and Wermers (1997) to remove the expected return components of common risk factors including SMB (Small-Minus-Big), HML (High-Minus-Low), UMD (Up-Minus-Down). Specifically, we independently sort the entire stock universe into quintile portfolios based on firm size, industry-adjusted book-to-market ratio, and industry-adjusted momentum. Next, we compute these 125 (i.e. $5 \times 5 \times 5$ ) valueweighted benchmark returns. The "cleaned" return is each stock's raw return minus the corresponding portfolio benchmark return, which can be called an abnormal return. The double-sorted portfolios are constructed as follows: in each month, all stocks are partitioned into tercile portfolios based on contemporaneous DGTW-adjusted returns. Low return, medium return and high return subsets correspond to $L R, M R$ and $H R$ groups respectively. We then form another three subsets in each return group individually based on stock-level news sentiment scores (i.e. $L S, M S$ and $H S$ refer to low, medium and high news sentiment subsets). By doing so, we end up with nine portfolios having different stock return and news sentiment characteristics. Next, we label each portfolio given its news return characteristics. For example, the $H R L S$ portfolio comprises the stocks with high contemporaneous stock returns and low news sentiment scores. Similarly, we define the $L R H S$ and $H R L S$ portfolios as the slowly incorporated news groups and the $H R H S$ and $L R L S$ portfolios as quickly incorporated news groups. The rationale is that a one-month window is enough for a stock to adjust prices given arriving news. If returns cannot match news sentiment, it can be accepted that stock prices did not catch the news signal promptly.

In Table 1, we report univariate analysis for the four types of news. The $L R H S, H R L S$, $L R L S$ and $H R H S$ portfolios are presented in each column. Specifically, both news sentiment scores and stock returns statistics exhibit considerable differences across the groups. For example, the LRHS portfolio has average stock return of $-12 \%$ per month and an average news sentiment score of 0.94 , which suggests that the stock in this portfolio tends to have negative returns and positive news. In other words, LRHS stocks are slowly incorporating good news. Consistent with this notion, we then find that the $H R L S$ portfolio exhibits negative news (the news sentiment score is -0.96) and positive return performance (average 
$15 \%$ per month), -1.17 news sentiment and $-15 \%$ monthly return for the $L R L S$ portfolio, and those of $H$ RHS are 1.02 and $15 \%$ respectively.

Moving to news volume, LRHS stocks release relatively fewer news articles compared to the other three counterparts (an average of 8.68 for $L R H S$ stocks, 11.75 for $H R L S$ stocks, 10.87 for HRHS stocks, and 11.71 for $L R L S$ stocks). The increasing number of news items in the following month can be observed for all four types of stock. This can be interpreted as suggesting that news stocks are likely to have a continuous information flow, especially SI news stocks. Readers may be concerned that these next month news items could more heavily drive their contemporaneous stock returns than those news released in previous periods. However, later in the robustness checks, we show that this is not the case by dropping all news observations in the portfolio holding periods.

Overall, it seems that our sequential double-sorted approach separates stocks into different types of news portfolios effectively.

Insert Table 1 here

\section{Empirical Results}

\subsection{Baseline Model}

We use a sequential double-sorted calendar-time portfolio approach to examine SI and QI news return predictability. In each month from July 1979 to December 2016, we partition all stocks into tercile portfolios based on their contemporaneous monthly DGTW-adjusted stock returns. The $L R, M R$ and $H R$ groups contain stocks with low returns, medium returns and high returns respectively. For each return portfolio, we further rank stocks into another three portfolios based on news sentiment scores. $L S, M S$ and $H S$ therefore collect stocks with low, medium and high new sentiment scores. Subsequently, we track the performance of each subset over the following month by computing their equally-weighted stock returns. By rolling this monthly window through the entire sample period, we obtain a time-series return performance for all nine portfolios. In Panel A of Table 2, it can be observed that news predictability monotonically decreases across different return groups. For example, the $L R$ and $H S$ portfolios predict a $1.45 \%$ return per month in the post-formation period whereas the $L R$ and $L S$ conjunction only achieves $1.05 \%$ every month. Similarly, it is also evident that the predicting power of return performance monotonically decreases for each news group from $L R$ to $H R$.

We further study SI and QI news effects in Panel B. SI is a long/short portfolio obtained

by buying slowly incorporated good news $(L R H S)$ stocks and selling slowly incorporated bad 
news $(H R L S)$ stocks. QI is a long/short portfolio obtained by buying quickly incorporated good news $(H R H S)$ stocks and selling quickly incorporated bad news $(L R L S)$ stocks. If investors do indeed react slowly to arriving news, we should observe that slowly incorporated news predicts stronger post-formation stock returns than quickly incorporated news.

Panel B of Table 2 supports this hypothesis: the SI news portfolio (i.e., the spread between $L R H S$ and $H R L S$ ) earns 101 basis points per month (t-statistic: 5.85) whereas the QI news portfolio (i.e., the spread between $H R H S$ and $L R L S$ ) has negative return predictability. The difference between the two, known as SMQ (Slow Minus Quick), gains 139 bps per month, which is significant at the $1 \%$ level.

Further, we perform a Fama-French regression analysis of these results and we report the alpha for the two news groups. Specifically, the risk-adjusted returns of the SI news portfolios remain consistently significant across all models, even when the short-term return reversal factor is included. This result suggests that the SI news effect cannot be simply interpreted as a short-term return reversal. In contrast, the QI news portfolio becomes insignificant after controlling for the Fama-French three factors and five factors. The alpha of the SMQ portfolio is significant across risk-adjusted models, suggesting that SI news indeed has stronger return predictability compared to QI news. Since most of the long-short portfolio returns come from SI news rather than QI news, we next focus on SI news predictability instead of SMQ in the regression analysis.

Insert Table 2 here

\subsection{Fama-MacBeth Regressions}

The asset pricing literature identifies a number of stock characteristics as future return predictors. Therefore, we are able to estimate several Fama and MacBeth (1973) regression models to study the predictability of our SI news and QI news on the following months stock returns after controlling for additional stock returns predictors. Specifically, we perform this regression model cross-sectionally in each month:

$$
\begin{array}{r}
\operatorname{EXRet}_{i, t+1}=\alpha+\beta_{1} * N S S_{i, t}+\beta_{2} *(N S S * S I N w s)_{i, t}+\beta_{3} *(N S S * Q I N w s)_{i, t} \\
+\beta_{4} * S I G d N w s_{i, t}+\beta_{5} * S I B d N w s_{i, t}+\beta_{6} * Q I G d N w s_{i, t} \\
+\beta_{7} * Q I B d N w s_{i, t}+X_{i, t}+\epsilon_{i, t}
\end{array}
$$

where $E X \operatorname{Ret}_{i, t+1}$ is the excess return of stock i at time t+1. NSS is the news sentiment scores of stock i at time t. SIGdNws, SIBdNws, QIGdNws and QIBdNws are dummy 
variables if a stock has a news article identified as slowly incorporated good news, slowly incorporated bad news, quickly incorporated good news or quickly incorporated bad news. $N S S * S I N w s$ and NSS*QINws are the interaction terms where news sentiment scores multiply with the SINws or QINws dummy variables. The literature and previous sections in this paper imply a positive $\beta_{2}$ and a negative $\beta_{3}$ coefficient on the interaction variables $N S S * S I N w s$ and $N S S * S I N w s$ respectively. In the $X$ vector, a number of control variables are added to capture various stock characteristics. Specifically, we first include $S I Z E$ and $B T M$ to control for the Fama and French (1993) predictors. LRET is the lagged one-month stock return to control for short-term reversals. Furthermore, $M O M$ is added in order to capture momentum effects, which is computed by taking past twelve-month cumulative return with at least eight-month valid observations. BET $A$ is included and computed by following Scholes and Williams (1977); Dimson (1979). We include IVOL (Idiosyncratic volatility) in the regression motivated by $\mathrm{Fu}(2009)$, who argues that idiosyncratic volatility represents how fast the firm-level information is incorporated into stock prices. We also add $I L L I Q$, a firm-level illiquidity proxy by Amihud (2002), which is computed by the average value of daily absolute stock returns divided by the dollar trading volume over the previous year.

Table 3 reports all primary variable coefficients from the three regression specifications. First, the $N S S$ positively predicts future returns, indicating that our news articles are indeed informative. Second, our SIBdNws and NSS*SINws variables are statistically significant under all regression specifications. In particular, the coefficient of NSS*SINws is 0.2004 (t-statistic $=2.21$ ) whereas the $N S S * Q I N w s$ term is insignificant. The positive $S I B d N w s$ coefficient suggests that the return continuation mainly comes from slowly incorporated bad news rather than good news occurring during the formation period. Comparing the magnitudes of $N S S$ and $N S S * S I N w s$, the $N S S * S I N w s$ term is more than double that of $N S S$ (0.2004 for $N S S * S I N w s$ vs 0.0959 for $N S S)$. All three specifications include a battery of control variables. Collectively, these tests confirm that our primary news variable, $N S S * S I N w s$, has strong stock return predictability and is robust to the incorporation of a number of control variables.

\subsection{Robustness Checks}

\subsubsection{Alternative Information Incorporation Measure}

Another measure of news incorporation would be to examine beta coefficients between the contemporaneous stock return and news sentiment scores. Inspired by the calculation of market beta in the CAPM model as in (Frazzini and Pedersen, 2014), we regress the daily 
news sentiment score on the corresponding stock return in a monthly rolling OLS regression model to obtain the coefficient. As such, it should improve measurement accuracy when the data frequency is on a daily basis. The regression equation is presented as follows:

$$
\operatorname{Ret}_{i, t}=\alpha+\beta * N S S_{i, t}+\epsilon_{i, t}
$$

where $\operatorname{Ret}_{i, t}$ is the daily return of stock $i$ on date $t . N S S_{i, t}$ is the daily pessimism value of stock-level news for stock $i$ on date $t$. This regression is then performed using a rolling monthly window. As a result, we obtain time-varying beta parameters between the stock return and news sentiment for each stock and each calendar month. To address the concern of overnight news or weekend news, which may have lagged return impacts and therefore might not be captured by our regression model, we allow a lagged three-trading-day window to capture market lagged reactions. For example, Monday night news will not have return impacts until Tuesday morning. Friday night news will also not influence stock returns until the next Monday when the market opens. It is then believed that our time-varying beta should capture all these delayed news reactions. Moreover, we only include a stock in the sample when it has at least five different news stories on five different trading days in the case of our regression having sparse observations. As a result, a steep sloping coefficient $\beta$ indicates news that is quickly incorporated, whereas a gentle slope implies slow information incorporation.

To trace the performance of different coefficients between the daily news sentiment score and daily contemporaneous stock returns, we employ a single-sorted calendar-time portfolio approach with a one-month rolling window. Specifically, in each month, we partition stocks into three terciles based on the $\beta$ coefficients (i.e., LoBETA, MeBETA and HiBETA portfolios). Naturally, the higher is the coefficient, the quicker the stock return responses. The top portfolio HiBETA then contains high beta coefficients, suggesting that news is incorporated quickly into stock prices. The bottom group, LoBET A, comprises those stocks with low beta coefficients, which indicates slow information incorporation. Finally, equallyweighted portfolio returns are computed during the post-formation period for the three portfolios separately.

The result of this alternative definition is reported in the Panel A of Table 4. The coefficient of the top portfolio (SINws group) is 1.28, which is significant at the $1 \%$ level, whereas the QINws portfolio achieves 80 bps per month ( $t$-statistic: 2.27 ). The Slow-MinusQuick (SMQ) portfolio reports an average 49 bps in each month, which is significant at 1\%. Compared to the SMQ portfolio constructed in the first way (94 bps per month), the overall profitability of SMQ created by news beta is halved. Presumably, our sample size is significantly reduced with a number of small size stocks excluded due to the fact that the 
stock included in calculation must have at least five news stories published on five different days in a month. It is unlikely that small firms have more than five different news releases in any month. Although this implies that the SI news effect is partially contributed by the small size effect, our SI news theory, on the other hand, seems to be more convincing under these two different designs.

\subsubsection{Further Robustness Checks}

We examine the robustness of our primary SI and QI news definitions. The sequential double-sorted of SI and QI news leads us to a potential issue. Since news sentiment scores and stock returns are positively correlated, the second sort on returns may create further variation in the next month's stock performance. As such, we perform an independent double-sorted on news sentiment and stock returns in the first robustness test. The SI and QI news defined by independent double-sorted displays the same pattern as those in Table 2. with return predictability achieving 100 bps (t-statistic=5.80) for SI news and -40 bps for QI news.

A potential concern regarding our findings is that the effect is largely driven by penny stocks. To avoid the bid-ask bounce and illiquidity, we exclude stocks whose prices are below $\$ 5$ per share at the end of each particular formation month. As panel B of Table 4 shows, the SI news effect still holds, albeit with reduced magnitudes.

One could argue that the predictability of SI news is due to a number of news articles arriving in the subsequent months. This might be true given the fact that news volume increases over time, see Table 1. The SI news effect could be driven by news released in the holding period rather than caused by the news in the previous formation period. To address this concern, we eliminate all news observations occurring within the holding periods. As can be seen in Panel C, the SI news effects remain statistically significant.

In addition, we attempt to quantify news sentiment by different sentiment indicators, or even different techniques. To mitigate the concern that some news items contain high volumes of both positive and negative sentiment words and lead to low levels of pessimism (i.e. Neg - Pos), we also report the results measured by only employing either $N e g$ or Pos indicators by the Loughran and McDonald (2011) dictionary method. Furthermore, we attempt to apply the different sentiment analysis tool. Earlier methodologies have been criticised in three main ways: First, the underlying bag-of-words model only detects single words as the leading judgment of sentiment analysis. It fails to take into account that some sentences contain "navigating words" such as doesn't, don't, can't, etc., which can change the sentiment of the entire sentence. Second, this model fails to consider "modifier words"

such as really, too much, etc. as these words or phrases sometimes enhance the positive 
and negative tone. Third, without analyzing grammatical structures, the Loughran and McDonald (2011) dictionary method finds it difficult to deal with part-of-speech tagging $5^{5}$ For example, the firm-specific news of company "Best buy" will be more positive than others given its firm name contains a positive sentiment word "Best". To address these pitfalls and the potential bias caused by them, we employ the Google Natural Language API as an alternative sentiment analysis ${ }^{6}$ Overall, the results remain quantitatively similar.

As for any definition, our measure of SI and QI news is somewhat subjective. For instance, we could examine the slowly incorporated news effect with a one-week time interval instead of a one-month window with or without matching returns. In our sample, SI news predicts a 53 bps return on a weekly basis (equivalent to $2.21 \%$ per month), compared to $1.01 \%$ using monthly windows. QI news exhibits similar patterns (-0.79\% per month). The rationale behind this finding is that the relevance of news is time-limited and its effects will fade away over longer horizons.

Collectively, the above robustness checks of the SI news effect should eliminate concerns of data mining or biased measures. In the next subsection, we study the time-variation of SI news effects within our sample.

Insert Table 4 here

\subsubsection{Subsample Analysis}

Undoubtedly, technical advances have facilitated information dissemination, therefore reducing the gap between information released and information received by investors. If SI news is caused by information that travels slowly, we should observe that the predictive power of SI news has gradually diminished over time. To test this hypothesis, we evenly split our sample into four different periods, the first two of which might be termed pre-Internet and the later two are post-Internet periods. Within each period, we perform the same analysis as previously discussed above. In Table 5, SI news significantly predicts the next month's stock returns during all sub-sample periods (93 bps during 1979 to 1987, 108 bps between 1988 and 1997, 132 bps from 1998 to 2007 and 62 bps between 2008 and 2016), which are all significant. Interestingly, the largest magnitude of SI news emerges during the 1998-2007 period where the number of news items dramatically increases. Until the crisis period (i.e., 2008 - 2016), we observe a reduced SI news effect.

\footnotetext{
${ }^{5}$ Part-of-speech tagging is a computational linguistic method to label the category of words as noun, adverb, adjective, etc.

${ }^{6}$ The Google Natural Language API is a newly-built natural language processing tool by Google Cloud, details of which can be found at https://cloud.google.com/natural-language/.
} 
Given the relatively stable performance of SI news across each sub-sample, it is implausible to conclude that SI news is caused by the slow information dissemination hypothesis, at least not for the post-Internet period.

Insert Table 5 here

\subsubsection{Long-run Performance}

It is natural to ask whether SI news is informative or noisy. If our news source contains genuine information about a firm's fundamentals, the return predictability of SI news should not subsequently reverse in the long-run. On the other hand, QI news has incorporated this information into the market price and therefore we should not observe any further return movements.

To examine long-run performance, we conduct a calendar-time portfolio approach over four different holding periods as follows: 3 months (i.e., month 2 to month 4), 6 months (i.e., month 2 to month 7), 9 months (i.e., month 2 to month 10) and 12 months (i.e., month 2 to month 13). These post-formation periods all skip the first month. However, the current month (i.e., month 1 to month 2) is also included as a comparison. We again construct a SI news portfolio that buys stocks with low returns but high news sentiment (LRHS) and sells stocks with high returns but low news sentiment (HRLS), and a QI news portfolio comprising of buying HRHS stocks and selling LRLS stocks. These portfolios are then rebalanced monthly and their performance monitored over different holding periods. The results, reported in Table 6, show that all periods observe insignificant coefficients for SI news except the first post-formation period. It is evident that the return predictability of SI news does not reverse in the long run. Similarly, we can also observe that the slowminus-quick factor gains significantly during the post-formation period and these portfolio returns do not reverse in the following months.

On the other hand, the results for QI news are surprising as this effect starts obtaining profits even after just 6 months. Presumably, this is because QI news stocks tend to be prominent and more visible for investors and therefore lead to further momentum effects after which the informative role of news dies away. Here, readers should distinguish the effect between prominence channels and information channels where the former only provides visibility but the latter gives new information, as documented by Kaniel and Parham (2017). Unfortunately, it is difficult to find an appropriate technique to apply to distinguish the effects of these two channels in this setting.

Overall, the long-run performance test confirms that SI news does contain new information and indeed this is incorporated into the market at a later stage. 
Insert Table 6 here

\subsubsection{Trading Strategy}

Our findings could potentially have useful implications for practitioners. In this subsection, we evaluate the impact of considering reasonable transaction costs on our trading strategy's profitability. The strategy we focus on is the slow-minus-quick portfolio that has both long and short positions. Since it is difficult to obtain precise transaction cost estimates for each trade, we therefore make a rough assumption that each trade incurs a total cost between 10 and 100 bps. This estimated cost will include all necessary expenses such as commissions, exchange fees, bid/ask spreads, market impact costs, and occasionally taxes. To recalculate the trading strategy returns, we trace the position of each stock included in our portfolio per month. A transaction cost will be incurred if a stock's position is opened or closed during the formation month. A double transaction cost will be incurred if a stock's position changes from buy to sell or from sell to buy. No transaction cost will be recorded if a stock stays in the portfolio and the position remains unchanged. Table 7 presents the abnormal and raw monthly trading returns under different cost assumptions.

As we can see from Table 7 , the profitability of the trading strategy gradually declines and becomes negative after accounting for 100 bps per transaction. It is likely that sophisticated investors can keep transactions costs to a low level or manage a refined trading strategy using different weighting schemes that might achieve better profits, and for such investors, the trading strategy would still be profitable net of costs. At a minimum, our paper sheds some light on one possible avenue for employing a news-based trading strategy for practitioners.

\subsection{Limited Attention Theory?}

\subsubsection{Conventional attention proxies}

Since these news portfolios exhibit cross-sectional differences in future return performance, we should ask what drives this cross-sectional difference of stock returns. One explanation regarding market delayed reactions is limited-attention theory. The growing literature of this strand includes Engelberg and Gao (2011) on the volume of Google searches for stock names, Da et al. (2014) on continuous information and momentum effects, and Fang and Peress (2009) on non-news stock returns. The theory predicts that investors under-react regarding stocks with low volumes of attention and thus the following return predictability is the result of this delayed reaction. Intuitively, stocks with small size, low media coverage, 
low turnover and low analyst coverage are generally associated with a poor information environment. In other words, it is information asymmetry that slows down investors' perceptions of arriving news. If so, we would expect that our SI news effects are concentrated in the low attention-grabbing stocks whereas QI news stocks would receive a relatively high volume of attention.

In this section, we employ four different investor attention proxies to study SI news effects following the previous literature (in particular (Da et al., 2014; Huang, 2018), which includes size, media coverage, trading volume and analyst coverage. We first examine the cross-sectional difference between small and large firms. To do so, we perform a double-sorted and construct calendar-time portfolios. Specifically, we rank the firm's market capitalisation values and partition these firms into either small size groups or big size groups before constructing SI and QI news portfolios. The market capitalization $(S I Z E)$ is computed by taking the natural logarithm of stock market values re-balanced at the end of June. We then form our SI and QI portfolios with small size and big size groupings. The next-month stock return performance is then traced for each month and the tabulated results are reported in the panel A of Table 8 .

As Table 8 shows, it is possible to observe that small firms predict higher returns in the following month compared to large firms. Statistically, SI news earns returns more than three times higher among small firms than large firms - 161 basis points versus 50 basis points respectively. The difference between the two the subsets is significant at the $1 \%$ level (with a $t$-statistic of 4.54). This suggests that SI news effects are concentrated in small sized firms, and this finding is consistent with limited-attention theory. However, there is no evidence for cross-sectional differences between small and big firms with QI news. Finally, our SMQ factor also positively confirms the SI news effect.

Following the literature on the impact of media attention (e.g., (Fang and Peress, 2009 , Hillert et al., 2014)), changes of media coverage are often applied as the representation of investors' attention. Stocks with higher $\Delta$ media coverage can naturally diffuse information in a way which is much quicker than lower $\Delta$ media covering stocks. Thus, SI news is more likely to be observed among low-attention stocks and QI news concentrated in high-attention stocks. Empirically, Panel A supports this limited-attention theory. With the monthly $\Delta$ media coverage shifting from low to high, SI news predicts next-month returns from 144 basis points per month to only 9 bps. The difference between the two coverage groups is significant at the $1 \%$ level. The SMQ factor also suggests that information diffusion is likely to be slower within the low media volume portfolio $(2.21 \%$ with a $t$-statistic of 7.56 for the cross-sectional difference between low and high media coverage groups), which is consistent with limited attention theory. 
Continued Panel A also tests the hypothesis regarding whether stocks with lower trading volume predict higher SI news profitability. The literature documents that trading volume can be a proxy for investor attention (Barber and Odean, 2007). To perform this test, we again construct a double-sorted calendar-time portfolio by employing stock-level trading volume. The variable is calculated as the natural log of the average share volume divided by the number of shares outstanding over each month using daily data. We then trace the portfolio performance by a rolling one-month window to observe SI news effects under either high or low trading volume groups. In the Table 8, we report all coefficients with $t$ statistics for each subset of stocks. Specifically, SI news stocks again earn $1.36 \%$ per month $(t$-statistic $=8.94)$. The difference in profitability between low and high turnover SI news is statistically significant at the $1 \%$ level. This is consistent with our theory that stocks without active trading activities are more likely to be under an investor's attention radar. Overall, comparing low and high turnover profits, we can conclude that low trading volume stocks are associated with higher SI news profitability.

Finally, we examine how analyst coverage is associated with cross-sectional difference in SI news predictability. The literature uses analyst coverage as a proxy for investor attention (Hirshleifer and Teoh, 2003). If investor inattention slows down information incorporation from news articles, the predictability should be concentrated among firms with low analyst coverage. The analyst coverage data is retrieved from Datastream for one-year forward earnings per share forecast for each firm. The sample is then divided into two groups based on the median number of analysts covering the stock, before which SI and QI news stock portfolios have been constructed in each month. In the continued Panel A, the performance of each portfolio has been reported. Stocks with low analyst coverage have higher levels of SI news compared to those with high coverage $-1.03 \%$ and $0.57 \%$ per month respectively. The $t$-statistic of low-minus-high spread is 1.19 , which is significant at the $5 \%$ level. In contrast, there is no evidence of QI news effects in either low or high sub-samples.

To summarise, four different investor attention proxies consistently support limitedattention theory, which indicates that SI news predictability is positively associated with low investor attention. In the next section, we will examine this theory with further tests.

Insert Table 8 here

\subsubsection{Google SVI and Bloomberg AIA attention proxies}

Although our empirical results positively confirm limited attention theory, we have had to assume that investors would have paid attention to the news if a company's name is mentioned. To address this issue, we further study limited-attention theory by utilising two 
direct attention proxies: Google Search Volume Index and Bloomberg news reading activity (AIA, i.e., abnormal Institutional investor Attention).

The direct attention proxies (Google SVI and Bloomberg AIA) have been proposed and studied in the literature, and have provided compelling evidence involving certain financial variables (Engelberg and Gao, 2011; Ben-Rephael et al., 2017). The Google SVI directly measures investor attention by using aggregated web users searching frequency based on Google search engines. That is to say, Google will count the number of visits for a particular key word during a time period. For instance, users might type "Apple Inc" and look up news related to the firm, which then is recorded and presented by the Google Search Volume Index (SVI). As shown in Figure 2 below, the SVI index of the key word Apple Technology company rises to a the peak of 100 on September 12, 2018 when the main launch event was held by Apple. As a consequence, this SVI index brings a direct linkage between the interest of the general public and firm-level news events.

Insert Figure 2 here

On the other hand, each Bloomberg terminal provides a news reader function where the news reading activity of any firm is monitored on daily basis. Due to the financial cost and required expertise of using Bloomberg, most terminal users are from the financial services sector, working as portfolio managers, stock analysts, or traders, etc. In other words, Bloomberg news reading activity is highly likely to represent institutional investor attention compared to the Google search engine which tends to represent retail investor attention.

To download Google SVI data, we use a Python web crawler to automatically send keywords (firm legal names) and retrieve data for each firm following certain procedures. Due to the mechanism of this data request, Google censors often return empty values for certain firm names. We then conduct several techniques to address this issue, the details of which can be found in the Appendix. Although given the fact that misrepresentation and bias of our data can exist, we believe that such issues have been minimised in this case. Finally, for a total number of 7,864 U.S. firms, we have evidence for 4,545 firms. As for the Bloomberg AIA data, we follow the procedure by Ben-Rephael et al. (2017) in which they download the Russel 3000 stocks from the year 2010 forwards 7 We then move to data pre-processing. Specifically, Bloomberg news reading activity data is a time-series measure of the rolling prior 30-days terminal users reading activity on an hourly basis. The value is 0 , 1, 2, 3 or 4 if the rolling average is below $80 \%$, between $80 \%$ and $90 \%$, between $90 \%$ and $94 \%$, between $94 \%$ and $96 \%$, and above $96 \%$ respectively. Following the method in Ben-Rephael et al. (2017), the AIA measure is a dummy variable which takes the value of zero when the

\footnotetext{
${ }^{7}$ Bloomberg AIA data is missing for the periods 12/6/2010 - 1/7/2011 and 8/17/2011 - 11/2/2011.
} 
score is 0,1 , or 2 and a value of one otherwise. To be consistent with Bloomberg AIA, we also assign the score for the Google SVI data based on the same method. The Google ASVI (Abnormal SVI) value will be one if the corresponding score is 3 or 4 and zero otherwise. These procedures allow us to capture the right tail of the distribution.

With these two attention proxies, we then ask whether low attention could explain stronger news predictability, particularly for slowly incorporated news. To examine this, we conduct a calendar-time portfolio approach with one trading day as a formation period and use the following ten trading days as a holding period for either the high or the low attention sub-sample. We change the research setting in this case for two reasons: first, both Google ASVI and Bloomberg AIA are reported on a daily basis and have been scaled in a proprietary manner prior to downloading. We are cautious to keep the natural data frequency in order to capture investor attention precisely. Second, due to the sample range, our period examined approaches recent years and both the SI and QI effects become weaker, as discussed in Section 4.3.3. The weaker effects might be partially attributed to advanced newswire transmissions such as Twitter, which speed up information dissemination. Overall, daily-basis settings can better capture the SI news effects.

Moreover, to address the concern that part of the SI news is released around the market closing bell and investors do not have enough time to fully digest it, we therefore categorise the news on the date $t$ at least 30 minutes prior to the market closing and label them on the date $t+1$ otherwise. To trace both SI and QI news portfolio performances, we again employ a double-sorted calendar-time portfolio approach. Specifically, we first sort stocks into either high or low attention groups based on stock-level attention values. We then form SI and QI news portfolios based on contemporaneous stock returns and news sentiment scores. The SI news portfolio is constructed by buying stocks with bad returns but good news and selling stocks with good returns but bad news; the QI news portfolio is formed by buying good stocks for both returns and news $(H R H S)$ and selling bad stocks $(L R L S)$. These portfolios are rebalanced each trading day and the performances are traced over the next ten trading days.

In the Table 8, it is possible to observe that Google ASVI predicts a stronger SI news effect. The difference between the low and high Google ASVI is even significant at the $1 \%$ (with $t$-statistic 4.44). The coefficients for the QI news subgroup are nearly zero (all statistically insignificant). Unfortunately, we do not observe any significant evidence for the Bloomberg AIA (our proxy for institutional investor attention). The results, therefore, suggests that it is retail investors rather than institutional investors for whom genuine news slips under their radar.

A further test is conducted to examine the relationship between SI news and retail at- 
tention. Figure 3 nicely visualises the interaction between SI news and retail attention. To perform a CAR analysis, we compute the characteristics-adjusted return based on (Daniel et al., 1997) and donated as DGTW. The slowly incorporated good news and bad news without retail attention achieves the highest and lowest abnormal returns respectively, while the return of news under retail attention lies in between. As a consequence, direct attention proxies allow us to take a close look at how limited investor attention is associated with SI news effects.

Insert Figure 3 here

\subsection{Complexity and Informativeness?}

SI news effects can also potentially be explained by news characteristics. The literature identifies that variation in news content does affect market reaction (Dougal et al., 2012; Umar, 2008). For instance, (especially retail) investors might find a complex news article challenging, in the sense that they might be uncertain about how to interpret the news content. Likewise, an ambiguous news tone could also fail to give investors a clear trading signal, which therefore discourages them form quickly responding. On the other hand, investors might under-react to a short news article because it means a less comprehensive report about a corporate event. They are also more likely to be interested in earnings-related news since these news items contain more valuable information (Tetlock et al., 2008; Chen, De, Hu, and Hwang, 2014). If SI and QI news is driven by the nature of the news in this setting, we would expect that easily-understandable and more informative news predicts lower future stock returns. In other words, investors will react quickly to news stories with fewer ambiguous words, fewer complex sentences, more comprehensive content, and more earnings-related topics.

To capture the textual complexity of our news documents, we apply the fog index and weak modal words measures, respectively. The Fog index is one of the most commonly applied readability measures for firm's financial disclosures (Dougal et al., 2012; Lawrence, 2013; Loughran and McDonald, 2014). It captures document readability by computing the average sentence length and the percentage of complex vocabularies. Thus, the higher the Fog index value, the more complex the material is. Weak modal words were first introduced by Loughran and McDonald (2011) in their financial dictionary to gauge uncertain business tone. Words such as "maybe", "appears", "might" frequently shown in the news suggest that these stories are less likely to attract investors. For example, Ahern and Sosyura (2015) uses this word category to gauge merger and acquisition rumours. As a result, we argue these two proxies are commonly used in the literature and should be effective to measure 
complexity in this paper.

To measure the news informativeness features, we first utilize article length as a proxy for comprehensiveness, as suggested by You et al. (2017). A long news article tends to convey more useful information and helps (especially retail) investors better understand underlying events. Next, we assess news informativeness by categorizing the news topic as earningsrelated or non-earnings-related. Specifically, we detect keywords from each news article using the word stem "earn". We identify the topic of a news article related to earnings if at least one word stem "earn" is found. The rationale behind this is that an article mentioning the word stem "earn" contains more information about a firm's fundamentals and is more likely to be value-relevant (Tetlock et al., 2008). Overall, it can be argued that a news story with long length and more "earn" word stems represents greater informativeness.

To test our hypothesis, we examine the cross-sectional difference of news characteristics individually. Specifically, we first calculate the median level of weak tone at each time point, rank the stocks with higher weak tone into an Ambiguous group and lower weak tone into an Accurate group. Similarly, we rank more readable stocks into a Concise group and less readable stocks into a Complex group based on the median Fog index in each month. For article length, we cross-sectionally rank all stocks into Short and Long groups based on a median level of word counts in each month. Lastly, we split our sample into two groups: EarningsEx, where stocks without any news articles containing earnings topics are collected, and EarningsIn, where stocks with only earnings-related news articles are included. To examine the statistical difference between each group, we construct Ambiguous - Accurate, Complex - Concise, Short - Long, and EarningsEx - EarningsIn, respectively. If complexity and informativeness do affect investor trading behaviour, we expect that these four cross-sectional differences would be positively significant for the SI news portfolio. The equally-weighted portfolio return is then computed for each subset sample to trace its postformation performance.

Panel A of Table 9 reports the cross-sectional differences by textual complexity. The evidence is mixed: although the cross-sectional difference between ambiguous accurate news stocks is positively and statistically significant ( $t$-statistic=2.29 for SI news), there is no clear evidence showing a significant difference between complex and concise news. This indicates that SI news predictability is not likely to come from hard-to-read news articles. Moving to Panel B, it is evident that the cross-sectional difference between short news (less comprehensive) and long news (more comprehensive) is significant ( $t$-statistic of 2.70) for SI news stocks. Interestingly, when we split our sample into earnings-related and non-earningsrelated topics, the cross-sectional difference between these two is insignificantly different from zero. This suggests that SI news is not exclusively earnings irrelevant and at least contains 
some valuable information.

Collectively, it can be concluded that SI news tends to use ambiguous tone and reports less comprehensively but such stories are not too complex to read and are not completely earnings-irrelevant. The empirical results do not systemically support complexity and informativeness theory.

\section{Conclusions}

In this paper, we first distinguish a firm-level news type as slowly incorporated, whereby stock returns do not promptly respond to corresponding news content, or quickly incorporated, where stock return performance matches the news sentiment score. The feature of SI news, specifically, is having a good (bad) sentiment score but with bad (good) stock returns. A long/short portfolio is then constructed to capture the SI news effect as buying a stock with low returns but a high news sentiment score and selling a stock with high returns but a low news sentiment score. As a result, we find that this news-induced anomaly can achieve 139 basis points per month (equivalent to $16.68 \%$ per year).

The SI news effect can be explained by limited-attention theory. According to this theory, investors tend to focus on a few stocks instead of evenly dispersing their attention throughout the entire stock universe. This then leads to the phenomenon where a group of firm-related news items drop under an investor's radar. The stock returns thus react very slowly. In empirical tests, we proxy less investor attention by small size, low media coverage, low trading volume, low analyst coverage, low Google SVI and low Bloomberg AIA. The results, strikingly, show stronger stock return predictability for less attention-grabbing stocks.

The empirical results, however, do not support complexity and informativeness theory in which the nature of news might cause investors' slow reaction. Generally, the textual complexity of news content should influence investors' trading behaviour, particularly for retail investors, whereby they might have no idea how to interpret complex news items or how to respond to ambiguous news articles. In addition, a short news article tends to be less comprehensive in reporting underlying events and therefore discourages investors from responding quickly. An article that does not contain value-relevant information could also fail to make investors take interest. Yet the evidence does not align with this theory.

To conclude, our paper refines the role of news coverage regarding information dissemination as it relates to the large gap between "news supply" and "news demand". If investors keep their focus on high attention-grabbing stocks, even genuine news for low-attention stocks cannot guarantee readership. Perhaps, from the news providers' point of view, news a month ago is only fish and chip paper. However, it might not be the case for investors if 
a firm-related news article does not receive attention.

Our findings are of relevance to both academics and practitioners: For academics, we add to the literature that the predictable return pattern after news emerges will only exist when prior news sentiment scores and contemporaneous returns are mismatched. For practitioners, our refined predictive model based on both news and contemporaneous returns provides a promising avenue for a potentially profitable trading strategy. 


\section{References}

Ahern, Kenneth R, and Denis Sosyura, 2015, "Rumor has it: Sensationalism in financial media," Review of Financial Studies 28, 2050-2093.

Ahmad, Khurshid, JingGuang Han, Elaine Hutson, Colm Kearney, and Sha Liu, 2016, "Media-expressed negative tone and firm-level stock returns," Journal of Corporate Finance $37,152-172$.

Amihud, Yakov, 2002, "Illiquidity and stock returns: cross-section and time-series effects," Journal of Financial Markets 5, 31-56.

Barber, Brad M, and Terrance Odean, 2007, "All that glitters: The effect of attention and news on the buying behavior of individual and institutional investors," Review of Financial Studies 21, 785-818.

Ben-Rephael, Azi, Zhi Da, and Ryan D Israelsen, 2017, "It depends on where you search: institutional investor attention and underreaction to news," Review of Financial Studies 30, 3009-3047.

Boulland, Romain, François Degeorge, and Edith Ginglinger, 2017, "News dissemination and investor attention," Review of Finance 21, 761-791.

Caporale, Guglielmo Maria, Fabio Spagnolo, and Nicola Spagnolo, 2018, "Macro news and bond yield spreads in the euro area," European Journal of Finance 24, 114-134.

Chakrabarty, Bidisha, Ananth Seetharaman, Zane Swanson, and Xu Wang, 2018, "Management risk incentives and the readability of corporate disclosures," Financial Management $47,583-616$.

Chan, Wesley S, 2003, "Stock price reaction to news and no-news: drift and reversal after headlines," Journal of Financial Economics 70, 223-260.

Chen, Hailiang, Prabuddha De, Yu Jeffrey Hu, and Byoung-Hyoun Hwang, 2014, "Wisdom of crowds: The value of stock opinions transmitted through social media," Review of Financial Studies 27, 1367-1403.

Da, Zhi, Umit G Gurun, and Mitch Warachka, 2014, "Frog in the pan: Continuous information and momentum," Review of Financial Studies 27, 2171-2218. 
Daniel, Kent, Mark Grinblatt, Sheridan Titman, and Russ Wermers, 1997, "Measuring mutual fund performance with characteristic-based benchmarks," Journal of Finance 52, $1035-1058$.

Dimson, Elroy, 1979, "Risk measurement when shares are subject to infrequent trading," Journal of Financial Economics 7, 197-226.

Dougal, Casey, Joseph Engelberg, Diego Garcia, and Christopher A Parsons, 2012, "Journalists and the stock market," Review of Financial Studies 25, 639-679.

Engelberg, Joseph, and Pengjie Gao, 2011, "In search of attention," Journal of Finance 66, 1461-1499.

Engelberg, Joseph, R David McLean, and Jeffrey Pontiff, 2018, "Anomalies and news," Journal of Finance 73, 1971-2001.

Engelberg, Joseph E, and Christopher A Parsons, 2011, "The causal impact of media in financial markets," Journal of Finance 66, 67-97.

Engelberg, Joseph E, Adam V Reed, and Matthew C Ringgenberg, 2012, "How are shorts informed?: Short sellers, news, and information processing," Journal of Financial Economics $105,260-278$.

Fama, Eugene F, and Kenneth R French, 1993, "Common risk factors in the returns on stocks and bonds," Journal of Financial Economics 33, 3-56.

Fama, Eugene F, and Kenneth R French, 2017, "International tests of a five-factor asset pricing model," Journal of Financial Economics 123, 441-463.

Fama, Eugene F, and James D MacBeth, 1973, "Risk, return, and equilibrium: Empirical tests," Journal of Political Economy 81, 607-636.

Fang, Lily, and Joel Peress, 2009, "Media coverage and the cross-section of stock returns," Journal of Finance 64, 2023-2052.

Fedyk, Anastassia, and James Hodson, 2017, "When can the market identify stale news?," Harvard University Working Paper.

Frazzini, Andrea, and Lasse Heje Pedersen, 2014, "Betting against beta," Journal of Financial Economics 111, 1-25.

Fu, Fangjian, 2009, "Idiosyncratic risk and the cross-section of expected stock returns," Journal of Financial Economics 91, 24-37. 
Garcia, Diego, 2013, "Sentiment during recessions," Journal of Finance 68, 1267-1300.

Hadzic, Muris, David Weinbaum, and Nir Yehuda, 2015, "News content, investor misreaction, and stock return predictability," Syracuse University Working Paper.

Henry, Elaine, 2008, "Are investors influenced by how earnings press releases are written?," Journal of Business Communication 45, 363-407.

Hillert, Alexander, Heiko Jacobs, and Sebastian Müller, 2014, "Media makes momentum," Review of Financial Studies 27, 3467-3501.

Hirshleifer, David, Sonya Seongyeon Lim, and Siew Hong Teoh, 2009, "Driven to distraction: Extraneous events and underreaction to earnings news," Journal of Finance 64, 2289-2325.

Hirshleifer, David, and Siew Hong Teoh, 2003, "Limited attention, information disclosure, and financial reporting," Journal of Accounting and Economics 36, 337-386.

Huang, Jiekun, 2018, "The customer knows best: The investment value of consumer opinions," Journal of Financial Economics 128, 164-182.

Jegadeesh, Narasimhan, and Sheridan Titman, 1993, "Returns to buying winners and selling losers: Implications for stock market efficiency," Journal of Finance 48, 65-91.

Jegadeesh, Narasimhan, and Sheridan Titman, 1995, "Overreaction, delayed reaction, and contrarian profits," Review of Financial Studies 8, 973-993.

Jegadeesh, Narasimhan, and Sheridan Titman, 2001, "Profitability of momentum strategies: An evaluation of alternative explanations," Journal of Finance 56, 699-720.

Jiang, Hao, Sophia Zhengzi Li, and Hao Wang, 2017, "News momentum," Michigan State University Working Paper.

Kaniel, Ron, and Robert Parham, 2017, "Wsj category kings-the impact of media attention on consumer and mutual fund investment decisions," Journal of Financial Economics 123, $337-356$.

Kräussl, Roman, and Elizaveta Mirgorodskaya, 2017, "Media, sentiment and market performance in the long run," European Journal of Finance 23, 1059-1082.

Lawrence, Alastair, 2013, "Individual investors and financial disclosure," Journal of Accounting and Economics 56, 130-147. 
Loughran, Tim, and Bill McDonald, 2011, "When is a liability not a liability? textual analysis, dictionaries, and 10-ks," Journal of Finance 66, 35-65.

Loughran, Tim, and Bill McDonald, 2014, "Measuring readability in financial disclosures," Journal of Finance 69, 1643-1671.

Loughran, Tim, and Bill McDonald, 2015, "The use of word lists in textual analysis," Journal of Behavioral Finance 16, 1-11.

Scholes, Myron, and Joseph Williams, 1977, "Estimating betas from nonsynchronous data," Journal of Financial Economics 5, 309-327.

Tetlock, Paul C, 2007, "Giving content to investor sentiment: The role of media in the stock market," Journal of Finance 62, 1139-1168.

Tetlock, Paul C, 2010, "Does public financial news resolve asymmetric information?," Review of Financial Studies 23, 3520-3557.

Tetlock, Paul C, 2011, "All the news that's fit to reprint: Do investors react to stale information?," Review of Financial Studies 24, 1481-1512.

Tetlock, Paul C, Maytal Saar-Tsechansky, and Sofus Macskassy, 2008, "More than words: Quantifying language to measure firms' fundamentals," Journal of Finance 63, 1437-1467.

Umar, Tarik, 2008, "Complexity aversion when seeking alpha," University of Chicago Working Paper.

Wang, Ying, Bohui Zhang, and Xiaoneng Zhu, 2018, "The momentum of news," Working Paper, Central University of Finance and Economics.

You, Jiaxing, Bohui Zhang, and Le Zhang, 2017, "Who captures the power of the pen?," Review of Financial Studies 31, 43-96. 


\section{Appendix}

\subsection{Name-ticker News collection}

In this section, we address the issue that news might be less relevant to the firm by only matching tickers. We impose additional matching criteria roughly following Tetlock et al. (2008). Briefly, the procedure proceeds as follows:

1. Download a list of company names and tickers from CRSP (all common stocks traded on the NYSE, AMEX and NASDAQ between 1979 and 2016).

2. The firm name string must appear in the first 25 words of a news article including the headline.

3. The firm name must be detected at least twice in the main body of news stories.

4. News reports with fewer than 50 words are excluded.

We tweaked the firms' names depending on the searching quality we had. This is because CRSP provides a very unique and different name strings in comparison of the common names applied in the Dow Jones Newswire Database. The tweaking details are in the following:

1. CRSP puts space between the abbreviated letters. e.g., $F D X C O R P$. We delete the space in this case.

2. The firm name ends with Inc, Ltd, Corp, Co. Then the suffix will be removed. Note that we apply this rule to all sample firms including Apple Inc. We insist on doing so because the keyword Apple will not match many noise news reports related to apple the fruit after conditioning tickers.

3. We replaced the abbreviated words INTL, MFG, CHEM with International, Manufacturing and Chemical respectively.

4. The name string which ends with $N E W$ or $O L D$ to specify the company's status was tweaked to keep the only name before these words.

Overall, our sample of news items halves to only 4,530,243 non-repeated firm-level news stories and the number of sample stocks decreases to 12,072. The result remains consistent as beforehand. Unfortunately, it is tricky to define the relevance between firm-level news

and the firm. Relevance scores designed by databases such as LexisNexis and RavenPack seem to be unrealistic at this stage. 


\subsection{Google Search Volume Index collection}

Unlike Engelberg and Gao (2011) using a sample of Russell 3000 stocks, our sample extends to all U.S. common stocks and we also acknowledge the fact that not all stocks have a non-zero SVI. We therefore carefully deal with the potential bias and errors when retrieving the Google SVI from the Google Trends webpage. The procedure is as follows:

1. Instead of using firm legal names from the CRSP historical name file as Google censor keywords, we utilise these firm names as search inputs but look into the Google autosuggestion menu. The optimal keyword would be chosen if the category of a keyword is "company" or "corporation". The rationale behind this is to convert firm legal names to the names commonly searched by users or mentioned in the financial press.

2. The SVI data has been scaled by Google based on the sample range. In this paper, we set up a 90-day period for each data request and Google censors therefore return daily data.

3. To get rid of "noise" attention, the underlying search source is restricted to business news only. Given that investors could come from the outside of the U.S., geographical location is worldwide when downloading.

4. We improve the data quality by manually validating the firm name sought with the original one. If there is a significant difference that can be visualised, the data will be excluded from our sample.

In total, we finally obtain a 4,545-firm sample out of 7,864 targets. 
Fig. 1. Distribution of Firm-level News Observations

Distribution of the Number of firms with news items between 1979 and 2016

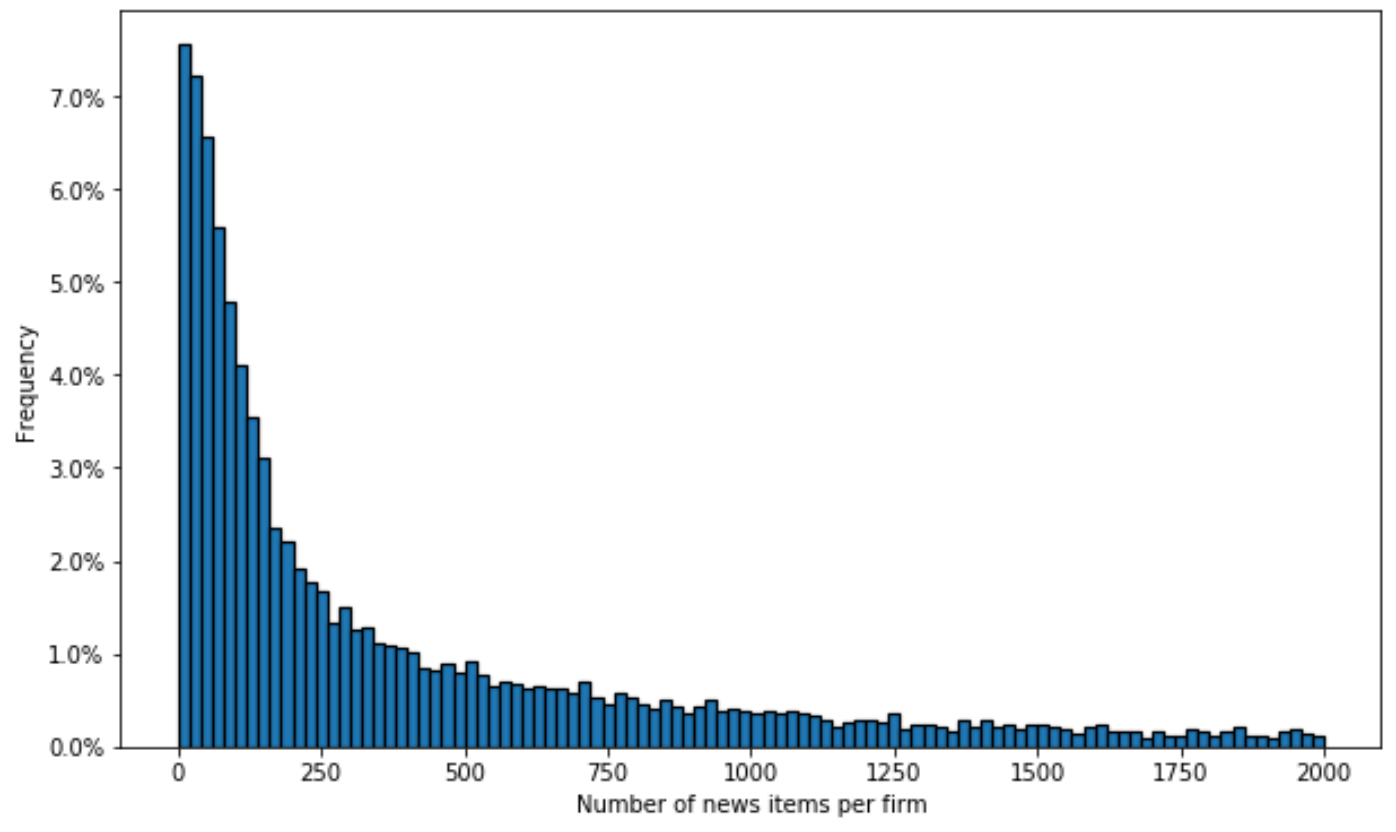

Figure 1 reports the frequency of news observations. X-axis is the number of news items for each firm. Y-axis is the percentage of firms among total sample. Sample period is between 1979 and 2016. 


\section{Fig. 2. Google Searching Volume Index for Apple Technology Company}

Figure 2 plots the search volume index of Apple Technology company by the Google search engine between 4 July and 30 September, 2018. The raw search volumes have been scaled and display as a time-series value between 0 and 100 .

Interest over time?

$\pm\langle<$

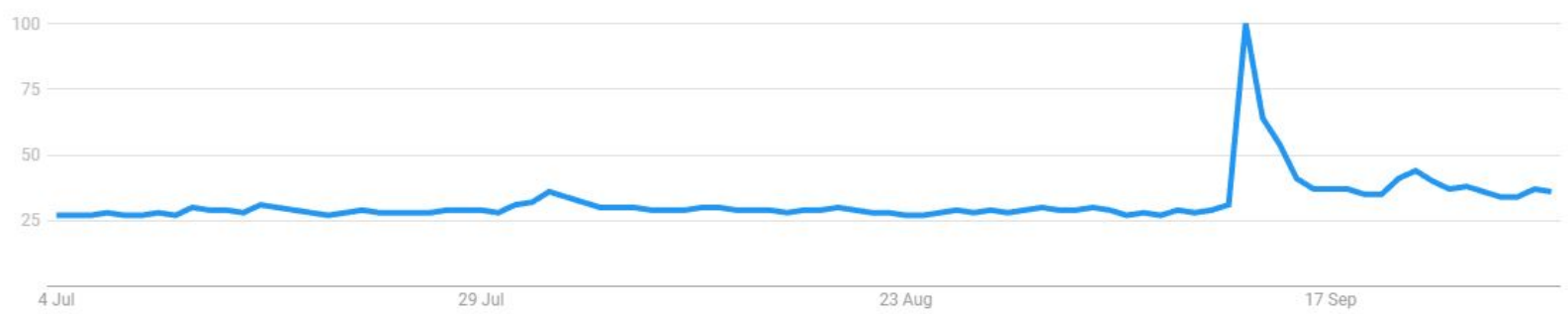


Fig. 3. Retail Attention and slowly incorporated News

Figure 3 plots the effect of slowly incorporated news under different retail attention which is proxied by Google ASVI data: (1) slowly incorporated good news (LRHS) under zero of retail attention (SIGdN_ASVI0). (2) slowly incorporated bad news (HRLS) under zero of retail attention (SIBdN_ASVI0). (3) slowly incorporated good news (LRHS) under one of retail attention (SIGdN_ASVI1). (4) slowly incorporated bad news (HRLS) under one of retail attention (SIBdN_ASVI1). The LRHS and HRLS news portfolios are defined as follows: On each trading day, firms are sorted into three groups based on their past abnormal returns, and then within each group, stocks are further ranked into three groups based on their news sentiment scores. We label the news on date $t$ at least 30 minutes prior to the market closing bell, otherwise it is classified on date $t+1$. SIGdN is slowly incorporated good news, donated as LRHS and SIBdN is slowly incorporated bad news donated as HRLS. The cumulative abnormal return is the DGTW-adjusted return computed by following (Daniel et al. 1997). The sample period ranges from 2004 to 2016 on a daily basis.

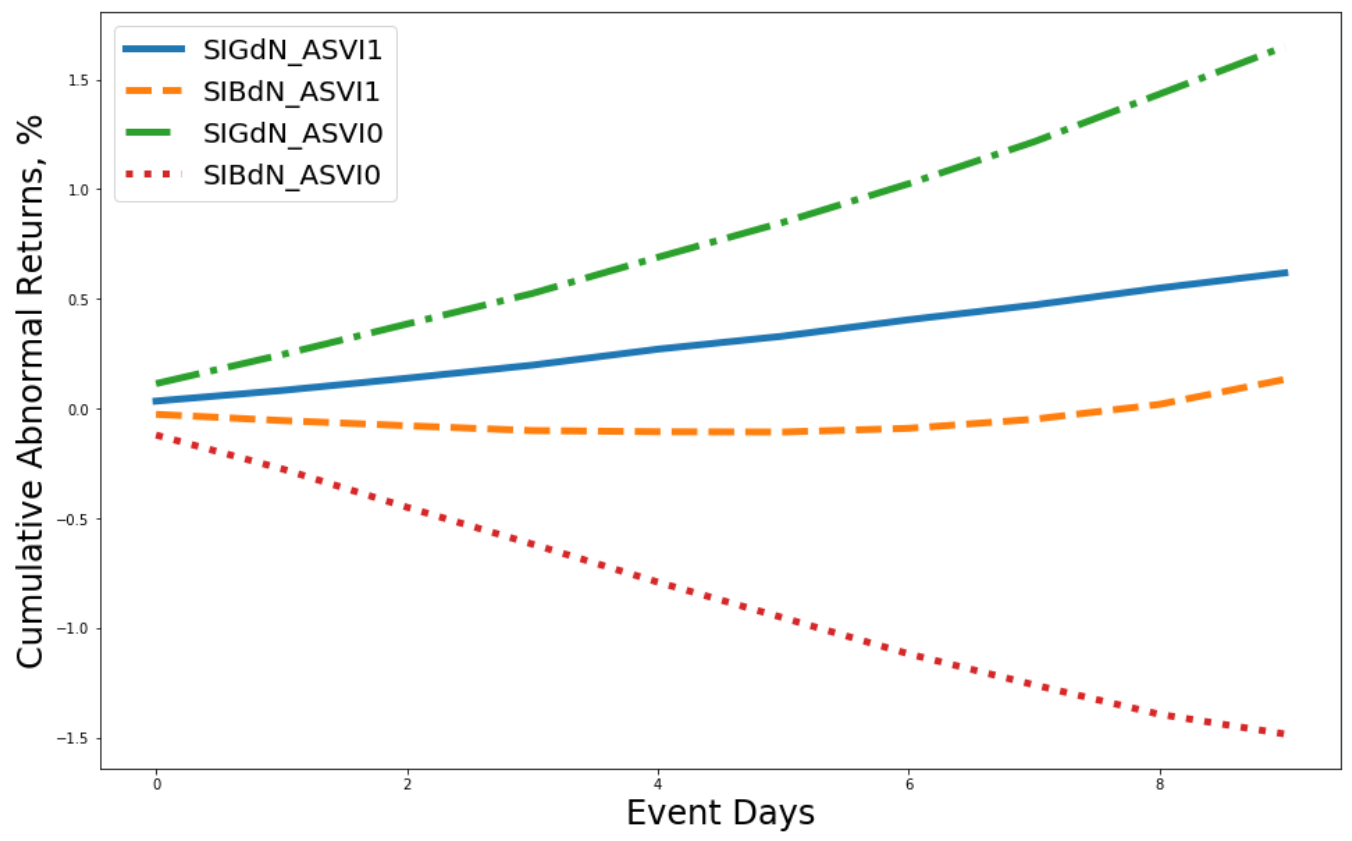


Table 1: Summary Statistics

Table 1 reports the summary statistics across all four types of news portfolios. The monthly sequential double-sorted approach is used. In each month, firms are sorted into three groups based on their past abnormal returns, and then within each group, stocks are further ranked into three groups based on their news sentiment scores. Abnormal return is the DGTW-adjusted return computed by following (Daniel et al., 1997). SIGoodNews is defined as those with low current stock returns but good positive news; SIBadNews are those with high current stock returns but bad negative news; QIGoodNews refers to news portfolios with high current stock returns and good positive news. QIBadNews are low stock return and bad news stocks. News Volume $_{t}$ is the number of news articles on current month.

\begin{tabular}{ccccc}
\hline & LRHS & HRLS & HRHS & LRLS \\
& SI Good News & SI Bad News & QI Good News & QI Bad News \\
\hline News Sentiment Score $_{t}$ & 0.94 & -0.96 & 1.02 & -1.17 \\
Abnormal Return $_{t}$ & -0.12 & 0.15 & 0.15 & -0.14 \\
News Volume $_{t}$ & 8.68 & 11.75 & 10.87 & 11.71 \\
News Volume $_{t+1}$ & 10.70 & 12.84 & 13.21 & 12.37 \\
\hline
\end{tabular}


Table 2: Slowly incorporated and quickly incorporated News

Table 2 Panel A reports the return and news predictability across terciles. The formation period and estimation period are both one month. In each month, firms are sorted into three groups based on their past abnormal returns, and then within each group, stocks are further ranked into three groups based on their news sentiment scores. Abnormal return is the DGTW-adjusted return computed by following (Daniel et al. 1997). All returns are reported in monthly average donated in percentages respectively. The sample period ranges from 1979 to 2016. Panel B reports time-series portfolio return with the risk-adjusted alphas including the Fama and French (1993) three-factor model, the Fama-French-Carhart four-factor model, the Fama and French (2017) five-factor model, a liquidity-augmented Fama-French-Carhart four-factor model, and short-term augmented Fama-French-Carhart four-factor model. The alpha estimates are obtained by regressing monthly portfolio excess returns on the monthly returns from the risk factors. The definition of SI and QI presents as follows:

$$
\begin{aligned}
& S I=L R H S-H R L S \\
& Q I=L R L S-H R H S
\end{aligned}
$$

where SI news is a long/short portfolio of buying slowly incorporated good news (LRHS) and selling slowly incorporated bad news (HRLS). QI news is a long/short portfolio of buying quickly incorporated good news (HRHS) and selling quickly incorporated bad news (LRLS). $t$-statistics are reported in parentheses and *,

\begin{tabular}{|c|c|c|c|c|c|c|}
\hline Panel A & \multicolumn{2}{|c|}{$\mathrm{HS}$} & \multicolumn{2}{|c|}{ Mid } & \multicolumn{2}{|c|}{ LS } \\
\hline LR & \multicolumn{2}{|c|}{$1.45 \%$} & \multicolumn{2}{|c|}{$1.22 \%$} & \multicolumn{2}{|c|}{$1.05 \%$} \\
\hline Mid & \multicolumn{2}{|c|}{$0.94 \%$} & \multicolumn{2}{|c|}{$0.77 \%$} & \multicolumn{2}{|c|}{$0.84 \%$} \\
\hline $\mathrm{HR}$ & \multicolumn{2}{|c|}{$0.67 \%$} & \multicolumn{2}{|c|}{$0.53 \%$} & \multicolumn{2}{|c|}{$0.45 \%$} \\
\hline Panel B & TS Ret & FF3F & $\mathrm{FF} 4 \mathrm{~F}$ & FF5Falpha & FF4F Liq & FF4F Rev \\
\hline $\begin{array}{l}\text { SI News } \\
\text { t-stat }\end{array}$ & $\begin{array}{c}1.01 \% * * * \\
(5.85)\end{array}$ & $\begin{array}{c}0.92 \% * * * \\
(3.66)\end{array}$ & $\begin{array}{c}1.09 \% * * * \\
(3.68)\end{array}$ & $\begin{array}{c}0.85 \% * * * \\
(3.00)\end{array}$ & $\begin{array}{c}1.09 \% * * * \\
(4.00)\end{array}$ & $\begin{array}{c}0.82 \% * * * \\
(4.11)\end{array}$ \\
\hline $\begin{array}{c}\text { QI News } \\
\text { t-stat }\end{array}$ & $\begin{array}{c}-0.39 \% * * \\
(-2.09)\end{array}$ & $\begin{array}{r}-0.27 \% \\
(-1.14)\end{array}$ & $\begin{array}{c}-0.64 \% * * * \\
(-2.70)\end{array}$ & $\begin{array}{r}-0.29 \% \\
(-0.94)\end{array}$ & $\begin{array}{c}-0.61 \% * * * \\
(-2.55)\end{array}$ & $\begin{array}{c}-0.38 \% * * \\
(-2.42)\end{array}$ \\
\hline $\begin{array}{c}\text { Slow-Minus-Quick } \\
\text { t-stat }\end{array}$ & $\begin{array}{c}1.39 \% * * * \\
(4.26)\end{array}$ & $\begin{array}{c}1.19 \% * * * \\
(2.59)\end{array}$ & $\begin{array}{l}1.73 \% * * * \\
(3.40)\end{array}$ & $\begin{array}{c}1.14 \% * * \\
(2.01)\end{array}$ & $\begin{array}{c}1.69 \% * * * \\
(3.70)\end{array}$ & $\begin{array}{c}1.20 \% * * * \\
(3.75)\end{array}$ \\
\hline
\end{tabular}
**, $* * *$ refers to the $10 \%, 5 \%$, and $1 \%$ significance levels respectively. 
Table 3: Predicting Stock Returns by slowly incorporated News and quickly incorporated News

Table 3 reports the stock return predictability of slowly incorporated news and quickly incorporated news based on various regression specifications. SINws and QINws are dummy variables if a news is slowly incorporated and quickly incorporated respectively. NSS*SINws and NSS*QINws are the interaction terms where NSS is a measure of news sentiment score. CONTROLS is a battery of control variables including LRET, SIZE, BTM, BETA, IVOL, MOM, ILLIQ. SIZE is computed by taking the natural logarithm of stock market values in each previous month. LRET is the lagged one-month stock return. $B T M$ is computed by taking the natural logarithm of stock market values divided by firm book values adjusted at each end of June. BETA is calculated following Scholes and Williams (1977); Dimson (1979). $M O M$ is the stock's most recent 12 -month cumulative returns. $I V O L$ is the idiosyncratic risk computed by the standard deviation of residuals from the Fama-French-Corhart four-factor model over the month using daily returns. ILLIQ is a proxy for stock liquidity based on Amihud 2002). The sample period ranges from 1979 to 2016 . $t$-statistics are reported in parentheses and ${ }^{*},{ }^{*},{ }^{* * *}$ refers to the $10 \%, 5 \%$, and $1 \%$ significance levels respectively.

\begin{tabular}{cccc}
\hline & \multicolumn{3}{c}{ Dep $=$ EXRet } \\
\cline { 2 - 4 } CONST & $2.0814^{* * *}$ & $2.0905^{* * *}$ & $2.0721^{* * *}$ \\
& $(6.22)$ & $(6.24)$ & $(6.22)$ \\
NSS & $0.0868^{* * *}$ & $0.1249^{* * *}$ & $0.0959^{* * *}$ \\
& $(3.09)$ & $(4.44)$ & $(3.11)$ \\
NSS*SINws & $0.2080^{* *}$ & & $0.2004^{* *}$ \\
& $(2.30)$ & & $(2.21)$ \\
NSS*QINws & & -0.1651 & -0.1351 \\
& & $(-1.63)$ & $(-1.30)$ \\
SIGdNws & -0.0555 & & -0.0488 \\
& $(-0.52)$ & & $(-0.45)$ \\
SIBdNws & $0.2653^{* *}$ & & $0.2768^{* *}$ \\
& $(2.36)$ & 0.1339 & $(2.44)$ \\
QIGdNws & & $(1.10)$ & $(1.28)$ \\
& & -0.1609 & -0.1262 \\
QIBdNws & & $(-1.13)$ & $(-0.87)$ \\
& & YES & YES \\
CONTROLS & YES & & \\
& & & \\
Nobs & 794317 & 794317 & 794317 \\
Adj_R ${ }^{2}$ & $6.12 \%$ & $6.14 \%$ & $6.19 \%$ \\
\hline
\end{tabular}


Table 4: Robustness Checks

Table 4 reports robustness checks of calendar-time portfolio tests. Panel A reports an alternative method of portfolio construction for returns and news sentiment scores. Panel B excludes stocks with prices below than $\$ 5$ per share. Panel C eliminates stocks with news observations on the holding period. Panel D measures news tone by different sentiment tools including Loughran and McDonald (2011) negative words and positive words, and the Google Natural Language Sentiment scores. Panel E reports portfolio performance on a weekly basis. $t$-statistics are reported in parentheses and $*, * *, * * *$ refers to the $10 \%, 5 \%$, and $1 \%$ significance levels respectively.

\begin{tabular}{|c|c|c|c|c|c|c|}
\hline Panel A & SI News & t-stat & QI News & t-stat & SMQ & t-stat \\
\hline News Beta & $1.28 \% * * *$ & $(5.16)$ & $0.80 \% * *$ & $(2.27)$ & $0.49 \% * *$ & $(2.36)$ \\
\hline Independent double-sorted & $1.00 \% * * *$ & $(5.80)$ & $-0.40 \% * *$ & $(-2.22)$ & $1.41 \% * * *$ & $(4.33)$ \\
\hline Panel B & SI News & t-stat & QI News & t-stat & SMQ & t-stat \\
\hline Price $>=\$ 5$ & $0.71 \% * * *$ & $(4.81)$ & $-0.16 \%$ & $(-1.08)$ & $0.87 \% * * *$ & $(3.22)$ \\
\hline Panel C & SI News & t-stat & QI News & t-stat & SMQ & t-stat \\
\hline Excluded subsequent news & $1.45 \% * * *$ & $(4.59)$ & $-0.98 \% * * *$ & $(-3.07)$ & $2.43 \% * * *$ & $(5.07)$ \\
\hline Panel D & SI News & t-stat & QI News & t-stat & SMQ & t-stat \\
\hline LM negative score & $0.99 \% * * *$ & $(5.47)$ & $-0.49 \% * * *$ & $(-2.68)$ & $1.47 \% * * *$ & $(4.43)$ \\
\hline LM positive score & $0.74 \% * * *$ & $(4.22)$ & $-0.69 \% * * *$ & $(-3.65)$ & $1.43 \% * * *$ & $(4.23)$ \\
\hline Google NL score & $0.78 \% * * *$ & $(4.53)$ & $-0.63 \% * * *$ & $(-3.32)$ & $1.41 \% * * *$ & $(4.30)$ \\
\hline Panel E & SI News & t-stat & QI News & t-stat & SMQ & t-stat \\
\hline Weekly frequency & $2.09 \% * * *$ & $(12.32)$ & $-0.79 \% * * *$ & $(-4.47)$ & $2.88 \% * * *$ & $(9.71)$ \\
\hline
\end{tabular}


Table 5: slowly incorporated and quickly incorporated News over Time

Table 5 reports the subsample analysis. The sample is split into four different periods: 1979 - 1987, 1988 1997, 1998 - 2007, 2008 - 2016 respectively. All returns are reported and converted into monthly averages in percentages. Panel A reports the SI and QI news portfolio returns on monthly. The definition of SI and QI presents as follows:

$$
\begin{aligned}
& S I=L R H S-H R L S \\
& Q I=L R L S-H R H S
\end{aligned}
$$

where SI news is a long/short portfolio of buying slowly incorporated good news (LRHS) and selling slowly incorporated bad news (HRLS). QI news is a long/short portfolio of buying quickly incorporated good news (HRHS) and selling quickly incorporated bad news (LRLS). $t$-statistics are reported in parentheses and *, $* *, * * *$ refers to the $10 \%, 5 \%$, and $1 \%$ significance levels respectively.

\begin{tabular}{ccccc}
\hline & $1979-1987$ & $1988-1997$ & $1998-2007$ & $2008-2016$ \\
\hline SI News & $0.93 \% * * *$ & $1.08 \% * * *$ & $1.32 \% * * *$ & $0.62 \% * *$ \\
t-stat & $(3.06)$ & $(4.75)$ & $(2.77)$ & $(2.20)$ \\
QI News & $0.14 \%$ & $-0.53 \% * *$ & $-0.51 \%$ & $-0.58 \% *$ \\
t-stat & $(0.47)$ & $(-1.97)$ & $(-1.03)$ & $(-1.65)$ \\
Slow-Minus-Quick & $0.79 \%$ & $1.61 \% * * *$ & $1.83 \% * *$ & $1.20 \% * *$ \\
t-stat & $(1.61)$ & $(3.96)$ & $(1.97)$ & $(2.06)$ \\
\hline
\end{tabular}


Table 6: The Long-run Performance of SI and QI News over Different Horizons

Table 6 reports the performance of slowly incorporated news and quickly incorporated news over different holding periods. The portfolio is constructed by sorting stocks into tercile portfolios over five different holding periods: one month, three months, six months, nine months and twelve months. In each month, firms are sorted into three groups based on their past abnormal returns, and then within each group, stocks are further ranked into three groups based on their news sentiment scores. Abnormal return is the DGTW-adjusted return computed by following (Daniel et al., 1997). The definition of SI and QI presents as follows:

$$
\begin{aligned}
& S I=L R H S-H R L S \\
& Q I=L R L S-H R H S
\end{aligned}
$$

where SI news is a long/short portfolio of buying slowly incorporated good news (LRHS) and selling slowly incorporated bad news (HRLS). QI news is a long/short portfolio of buying quickly incorporated good news (HRHS) and selling quickly incorporated bad news (LRLS). The sample period ranges from 1979 to 2016. $t$-statistics are reported in parentheses and $*, * *, * * *$ refers to the $10 \%, 5 \%$, and $1 \%$ significance levels respectively.

\begin{tabular}{ccccccc}
\hline Months & SI News & t-stat & QI News & t-stat & Slow-Minus-Quick & t-stat \\
\hline$[1,2]$ & $1.01 \% * * *$ & $(5.85)$ & $-0.39 \%^{* *}$ & $(-2.09)$ & $1.39 \% * *$ & $(2.43)$ \\
{$[2,4]$} & $-0.03 \%$ & $(-0.24)$ & $0.20 \%$ & $(1.54)$ & $-0.22 \%$ & $(-1.01)$ \\
{$[2,7]$} & $-0.07 \%$ & $(-0.83)$ & $0.20 \%^{*}$ & $(1.93)$ & $-0.28 \%$ & $(-1.64)$ \\
{$[2,10]$} & $-0.06 \%$ & $(-0.83)$ & $0.17 \%^{*}$ & $(1.79)$ & $-0.23 \%$ & $(-1.53)$ \\
{$[2,13]$} & $-0.09 \%$ & $(-1.30)$ & $0.14 \%^{*}$ & $(1.76)$ & $-0.22 \%^{*}$ & $(-1.90)$ \\
\hline
\end{tabular}


Table 7: The Sensitivity of Slow-Minus-Quick Trading Strategy Returns to Trading Cost Assumptions

Table 7 shows estimates of the trading strategy's profitability based on the Slow-minus-Quick portfolio after considering transaction costs. We recalculate the average monthly profitability for 10 alternative assumptions about an investor's round-trip transaction costs, namely: 10, 20,30 ..., and 100 basis points (bps) per trade. The abnormal return is based on the full sample raw return of the SMQ trading portfolio after regressing on the Fama-French five factors.

\begin{tabular}{ccc}
\hline Trading Costs (bps) & Abnormal Returns (\%) & Raw Returns (\%) \\
\hline 0 & $1.14 \%$ & $1.39 \%$ \\
10 & $0.99 \%$ & $1.24 \%$ \\
20 & $0.83 \%$ & $1.08 \%$ \\
30 & $0.68 \%$ & $0.93 \%$ \\
40 & $0.53 \%$ & $0.78 \%$ \\
50 & $0.38 \%$ & $0.63 \%$ \\
60 & $0.22 \%$ & $0.47 \%$ \\
70 & $0.07 \%$ & $0.32 \%$ \\
80 & $-0.08 \%$ & $0.17 \%$ \\
90 & $-0.23 \%$ & $0.02 \%$ \\
100 & $-0.39 \%$ & $-0.14 \%$ \\
\hline
\end{tabular}


Table 8 reports the performance of slowly incorporated news and quickly incorporated news under different information environments. In the panel A, we independently sort all stocks into two portfolios based on their most recent market capitalization (Size), current monthly change of media coverage, turnover ratio and analyst coverage. We report the "Small-Large" SIZE, "Low-High" $\Delta$ MEDIA, "Low-High" TURN, "Low-High" AstCvg spread profitability in the post-formation period. In Panel B, we independently sort all stocks into two portfolios based on their current investor attention index. We report the "Low-High" Google ASVI ATTN, "Low-High"Bloomberg AIA ATTN spread profitability in the following ten trading days. The Google ASVI is the Google Search Volume Index, which is a proxy for retail investor attention and Bloomberg AIA measures the Bloomberg users news reading activity, which represents institutional investor attention. The panel B coefficients are ten-trading-day cumulative returns in percentages. $t$-statistics are reported in parentheses and ${ }^{*},{ }^{*},{ }^{* * *}$ refers to the $10 \%, 5 \%$, and $1 \%$ significance levels respectively.

\begin{tabular}{|c|c|c|c|c|c|c|}
\hline \multirow[t]{2}{*}{ Panel A } & \multicolumn{3}{|c|}{ Size Subsamples } & \multicolumn{3}{|c|}{ MEDIA Subsamples } \\
\hline & SmallSIZE & BigSIZE & Small-Big & LowMEDIA & HighMEDIA & Low-High \\
\hline SI News & $\begin{array}{c}1.61 \% * * * \\
(6.58)\end{array}$ & $\begin{array}{c}0.50 \% * * * \\
(3.04)\end{array}$ & $\begin{array}{c}1.11 \% * * * \\
(4.54)\end{array}$ & $\begin{array}{c}1.44 \% * * * \\
(7.52)\end{array}$ & $\begin{array}{l}0.09 \% \\
(0.54)\end{array}$ & $\begin{array}{c}1.35 \% * * * \\
(7.10)\end{array}$ \\
\hline QI News & $\begin{array}{c}-0.61 \% * \\
(-1.92)\end{array}$ & $\begin{array}{c}-0.18 \% \\
(-1.07)\end{array}$ & $\begin{array}{c}-0.43 \% \\
(-1.50)\end{array}$ & $\begin{array}{c}-0.64 \% * * * \\
(-3.18)\end{array}$ & $\begin{array}{l}0.22 \% \\
(1.41)\end{array}$ & $\begin{array}{c}-0.86 \% \text { *** } \\
(-4.55)\end{array}$ \\
\hline Slow-Minus-Quick & $\begin{array}{c}2.22 \% * * * \\
(4.67)\end{array}$ & $\begin{array}{c}0.67 \% * * \\
(2.28)\end{array}$ & $\begin{array}{c}1.55 \% * * * \\
(3.65)\end{array}$ & $\begin{array}{c}2.08 \% * * * \\
(6.00)\end{array}$ & $\begin{array}{c}-0.13 \% * * * \\
(-0.48)\end{array}$ & $\begin{array}{c}2.21 \% * * * \\
(7.56)\end{array}$ \\
\hline \multirow[t]{2}{*}{ Panel A - Continued } & \multicolumn{3}{|c|}{ TURN Subsamples } & \multicolumn{3}{|c|}{ AstCvg Subsamples } \\
\hline & LowTURN & HighTURN & Low-High & LowAstCvg & HighAstCvg & Low-High \\
\hline SI News & $\begin{array}{c}1.36 \% * * * \\
(8.94)\end{array}$ & $\begin{array}{c}0.56 \% * * \\
(2.03)\end{array}$ & $\begin{array}{c}0.80 \% * * * \\
(2.95)\end{array}$ & $\begin{array}{c}1.03 \% * * * \\
(4.53)\end{array}$ & $\begin{array}{c}0.57 \% * * * \\
(3.06)\end{array}$ & $\begin{array}{c}0.46 \% * * \\
(1.99)\end{array}$ \\
\hline QI News & $\begin{array}{c}-0.34 \% * * \\
(-2.12)\end{array}$ & $\begin{array}{r}-0.29 \% \\
(-1.01)\end{array}$ & $\begin{array}{r}-0.04 \% \\
(-0.16)\end{array}$ & $\begin{array}{r}-0.08 \% \\
(-0.33)\end{array}$ & $\begin{array}{c}-0.20 \% \\
(-1.04)\end{array}$ & $\begin{array}{l}0.12 \% \\
(0.50)\end{array}$ \\
\hline Slow-Minus-Quick & $\begin{array}{c}1.70 \% * * * \\
(6.79)\end{array}$ & $\begin{array}{c}0.85 \% * \\
(1.71)\end{array}$ & $\begin{array}{c}0.85 \% * \\
(1.87)\end{array}$ & $\begin{array}{c}1.11 \% * * * \\
(2.76)\end{array}$ & $\begin{array}{c}0.77 \% * * \\
(2.33)\end{array}$ & $\begin{array}{l}0.34 \% \\
(0.94)\end{array}$ \\
\hline \multirow[t]{2}{*}{ Panel B } & \multicolumn{3}{|c|}{ Google ASVI ATTN Subsamples } & \multicolumn{3}{|c|}{ Bloomberg AIA ATTN Subsamples } \\
\hline & LowATTN & HighATTN & Low - High & LowATTN & HighATTN & Low - High \\
\hline SINws & $\begin{array}{c}0.05 \% * * * \\
(6.23)\end{array}$ & $\begin{array}{c}0.01 \% * * \\
(2.22)\end{array}$ & $\begin{array}{c}0.04 \% * * * \\
(4.44)\end{array}$ & $\begin{array}{c}0.02 \% * * \\
(2.24)\end{array}$ & $\begin{array}{l}0.00 \% \\
(0.28)\end{array}$ & $\begin{array}{l}0.01 \% \\
(0.85)\end{array}$ \\
\hline QINws & $\begin{array}{l}0.00 \% \\
(-0.15)\end{array}$ & $\begin{array}{l}0.01 \% \\
(1.22)\end{array}$ & $\begin{array}{c}-0.01 \% \\
(-1.12)\end{array}$ & $\begin{array}{l}0.00 \% \\
(-0.17)\end{array}$ & $\begin{array}{l}-0.01 \% \\
(-0.83)\end{array}$ & $\begin{array}{l}0.00 \% \\
(0.35)\end{array}$ \\
\hline Slow-Minus-Quick & $\begin{array}{c}0.05 \% * * * \\
(4.22)\end{array}$ & $\begin{array}{l}0.00 \% \\
(0.42)\end{array}$ & $\begin{array}{c}0.05 \% * * * \\
(3.92)\end{array}$ & $\begin{array}{c}0.02 \% * \\
(1.72)\end{array}$ & $\begin{array}{l}0.01 \% \\
(0.74)\end{array}$ & $\begin{array}{l}0.01 \% \\
(0.40)\end{array}$ \\
\hline
\end{tabular}


Table 9: SI and QI News in Different Nature of News

Table 9 reports the performance of slowly incorporated news and quickly incorporated news for different news characteristics. In Panel A, we independently sort all stocks into two portfolios based on textual complexity. In Panel B, we again sort all stocks into two portfolios based on news informativeness. We report the "Ambiguous-Accurate" Tone, "Complex-Concise" Readability, "Short-Long" Length, and "EarningsEx-EarningsIn" Topic spread profitability in the post-formation period. $t$-statistics are reported in parentheses and *, **, *** refers to the $10 \%, 5 \%$, and $1 \%$ significance levels respectively.

\begin{tabular}{|c|c|c|c|c|c|c|}
\hline \multirow[t]{2}{*}{ Panel A } & \multicolumn{3}{|c|}{ SI and QI News across Accuracy Subsamples } & \multicolumn{3}{|c|}{ SI and QI News across Readability Subsamples } \\
\hline & Ambiguous & Accurate & Ambiguous - Accurate & Complex & Concise & Complex - Concise \\
\hline SI News & $\begin{array}{c}1.05 \% * * * \\
(3.95)\end{array}$ & $\begin{array}{l}0.42 \% \\
(1.61)\end{array}$ & $\begin{array}{c}0.63 \% * * \\
(2.29)\end{array}$ & $\begin{array}{c}1.10 \% * * * \\
(5.34)\end{array}$ & $\begin{array}{c}0.81 \% * * * \\
(3.97)\end{array}$ & $\begin{array}{l}0.30 \% \\
(1.30)\end{array}$ \\
\hline QI News & $\begin{array}{c}-0.51 \% * * \\
(-2.08)\end{array}$ & $\begin{array}{l}0.02 \% \\
(0.07)\end{array}$ & $\begin{array}{c}-0.53 \%^{*} \\
(-1.91)\end{array}$ & $\begin{array}{c}-0.67 \% * * * \\
(-2.93)\end{array}$ & $\begin{array}{r}-0.32 \% \\
(-1.54)\end{array}$ & $\begin{array}{c}-0.34 \%^{*} \\
(-1.68)\end{array}$ \\
\hline Slow-Minus-Quick & $\begin{array}{c}1.55 \% * * * \\
(3.37)\end{array}$ & $\begin{array}{l}0.40 \% \\
(0.83)\end{array}$ & $\begin{array}{c}1.15 \% * * * \\
(2.55)\end{array}$ & $\begin{array}{c}1.77 \% * * * \\
(4.77)\end{array}$ & $\begin{array}{c}1.13 \% * * * \\
(3.29)\end{array}$ & $\begin{array}{c}0.64 \%^{* *} \\
(2.11)\end{array}$ \\
\hline \multirow[t]{2}{*}{ Panel B } & \multicolumn{3}{|c|}{ SI and QI News across Length Subsamples } & \multicolumn{3}{|c|}{ SI and QI News across Earnings Subsamples } \\
\hline & Short & Long & Short - Long & EarningsEx & EarningsIn & EarningsEx - EarningsIn \\
\hline SI News & $\begin{array}{l}1.29 \% * * * \\
(5.78)\end{array}$ & $\begin{array}{c}0.70 \% * * * \\
(3.62)\end{array}$ & $\begin{array}{c}0.58 \% * * * \\
(2.70)\end{array}$ & $\begin{array}{c}0.92 \% * * * \\
(5.33)\end{array}$ & $\begin{array}{c}0.77 \% * * * \\
(3.61)\end{array}$ & $\begin{array}{l}0.16 \% \\
(1.04)\end{array}$ \\
\hline QI News & $\begin{array}{c}-0.79 \% * * * \\
(-3.53)\end{array}$ & $\begin{array}{r}-0.19 \% \\
(-0.81)\end{array}$ & $\begin{array}{c}-0.60 \% * * * \\
(-2.60)\end{array}$ & $\begin{array}{c}-0.45 \% * * \\
(-2.35)\end{array}$ & $\begin{array}{r}-0.27 \% \\
(-1.36)\end{array}$ & $\begin{array}{l}-0.18 \% \\
(-1.09)\end{array}$ \\
\hline Slow-Minus-Quick & $\begin{array}{c}2.08 \% * * * \\
(5.40)\end{array}$ & $\begin{array}{c}0.90 \% * * \\
(2.45)\end{array}$ & $\begin{array}{c}1.18 \% \text { *** } \\
(3.74)\end{array}$ & $\begin{array}{c}1.38 \% * * * \\
(4.10)\end{array}$ & $\begin{array}{c}1.04 \% * * * \\
(2.90)\end{array}$ & $\begin{array}{c}0.34 \%^{*} \\
(1.65)\end{array}$ \\
\hline
\end{tabular}

